\title{
Review Article \\ Intra-Golgi Transport: Roles for Vesicles, Tubules, and Cisternae
}

\author{
José A. Martínez-Menárguez \\ Department of Cell Biology and Histology, Medical School, University of Murcia, 30100 Murcia, Spain \\ Correspondence should be addressed to José A. Martínez-Menárguez; jamartin@um.es
}

Received 17 December 2012; Accepted 7 January 2013

Academic Editors: J. C. Hay, R. Puertollano, T. Yazawa, and Y. Zhang

Copyright (C) 2013 José A. Martínez-Menárguez. This is an open access article distributed under the Creative Commons Attribution License, which permits unrestricted use, distribution, and reproduction in any medium, provided the original work is properly cited.

\begin{abstract}
The Golgi complex is considered the central station of the secretory pathway where cargo proteins and lipids are properly modified, classified, packed into specific carriers and delivered to their final destinations. Early electron microscope studies showed the extraordinary structural complexity of this organelle. However, despite the large volume of incoming and outgoing traffic, it is able to maintain its architecture, although it is also flexible enough to adapt to the functional status of the cell. Many components of the molecular machinery involved in membrane traffic and other Golgi functions have been identified. However, some basic aspects of Golgi functioning remain unsolved. For instance, how cargo moves through the stack remains controversial and two classical models have been proposed: vesicular transport and cisternal maturation. Since neither of these models explains all the experimental data, a combination of these models as well as new models have been proposed. In this context, the specific role of the cisternae, vesicles and tubules needs to be clarified. In this review, we summarize our current knowledge of the Golgi organization and function, focusing on the mechanisms of intra-Golgi transport.
\end{abstract}

\section{Introduction}

Eukaryotic cells are highly compartmentalized in organelles, which are surrounded by membranes. Every compartment has its own composition, structure, and function. However, these elements are not totally isolated because there is a continuous flow of components between them. Endocytic and secretory routes are complex processes involving formation, movement, and fusion with the specific targets of transport carriers. Palade was a pioneer in this field by establishing that newly synthesized proteins in the endoplasmic reticulum (ER) move to the Golgi complex (GC) and they are packed in secretory granules before being secreted [1]. Although this concept is a dogma in cell biology, some proteins bypass the GC on their way to the cell surface, a process known as unconventional trafficking [2]. The central role of the GC in the secretory pathway is nowadays understood $[3,4]$. The GC receives newly synthesized proteins and lipids from the ER. This cargo is classified, packed, and delivered to the final destination, but is extensively modified on the way, mainly involving the glycosylation of proteins and lipids. Recently, a key role in many cellular processes has been associated with this compartment including microtubule nucleation, signaling, and calcium homoeostasis [5]. In recent decades the molecular machinery involved in many of these processes has been identified. Progress in the field is directly related with the application of new methodologies such as live cell imaging [6-8], organelle proteomics $[9,10]$, functional genomics [11], high-resolution immunocytochemistry [12, 13], correlative light-electron microscopy [14], and electron tomography [15]. However, despite the huge amount of detailed information available, there are still many questions opened and some basic principles remained to be completely understood. This paper presents an overview of Golgi organization, focusing on the mode of intra-Golgi transport. For details of the topic treated in this paper and other aspects of Golgi function such as post-Golgi/TGN transport, signaling, structure in lower organisms, or behavior during cell death and division, many excellent reviews can be consulted $[5,16-$ 24].

\section{Golgi Organization}

Under electron microscopy, the GC can be unambiguously identified from its singular appearance. It is usually composed of 3-9 stacked flat cisternae forming the Golgi stack or dictyosome, surrounded by tubulovesicular elements [25-27] 


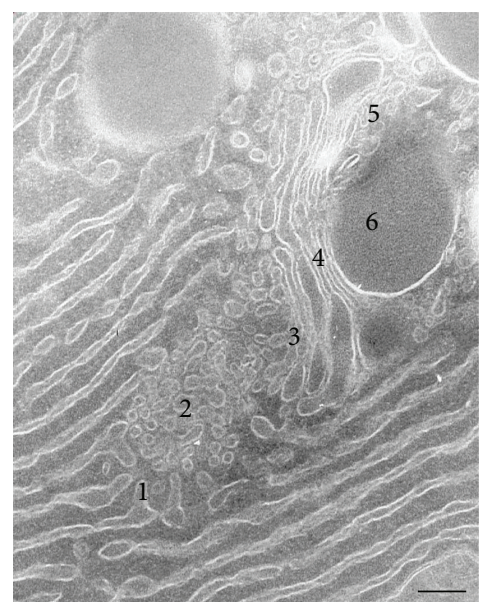

Figure 1: Cryosection of the Golgi complex of rat exocrine pancreatic cells. Typical image of a cross-sectioned Golgi complex. $1=$ endoplasmic reticulum exit site, 2 = tubulovesicular elements associated to ERGIC, 3 = tubular membranes associated with the CGN, $4=$ stack of cisternae, $5=$ TGN elements, $6=$ secretory granule. Bar $=$ $200 \mathrm{~nm}$.

(Figures 1 and 2). The stack of cisternae is considered the central domain of the GC. Cisternae are very narrow in the center and dilated at the lateral rims where they show coated buds. The low area/volume ratio favors interaction between the enzymatic machinery of membranes and the cargo. They often show fenestrations, sometime appearing as large holes that form wells [28]. The morphology of the stacked cisternae depends on the cargo. Thus, when protein synthesis is blocked, the cisternae are very thin and stacks show an onionlike organization [29]. The $\mathrm{pH}$ is also important and a low $\mathrm{pH}$ induces thin cisternae [30]. In most mammalian cells, Golgi stacks are laterally connected to form continuous ribbon. The reason for this, not known but could be related with advanced functions such as polarized secretion, cell motility, and signalling [31, 32]. The maintenance of the Golgi ribbon depends on the microtubular cytoskeleton and a balanced inward and outward transport. Microtubule depolymerization induced by nocodazole breaks the ribbon into ministacks [33], a process that is reversible, demonstrating that the GC is a high dynamic organelle. Interestingly, the Golgi ribbon appeared fragmented into ministacks in many neurological diseases including Parkinson's disease [16, 34, 35]. The lateral area of the stacks where one connects with another is known as the noncompact region. This shows a complex morphology and is filled with vesicles and other heterogeneous elements [36].

The composition of the cisternae is not homogeneous and it contains different sets of resident proteins. Based on this, Golgi stacks have been classically divided into cis, medial, and trans sides. Cis cisternae receive newly synthesized proteins and lipids from the ER, while cargo exits the organelle at the trans side, taking 10-20 minutes to traverse the stack. ER elements tightly associated with the transmost cisternae have been described, the role of which is not known but may be related with the direct transfer of lipids between

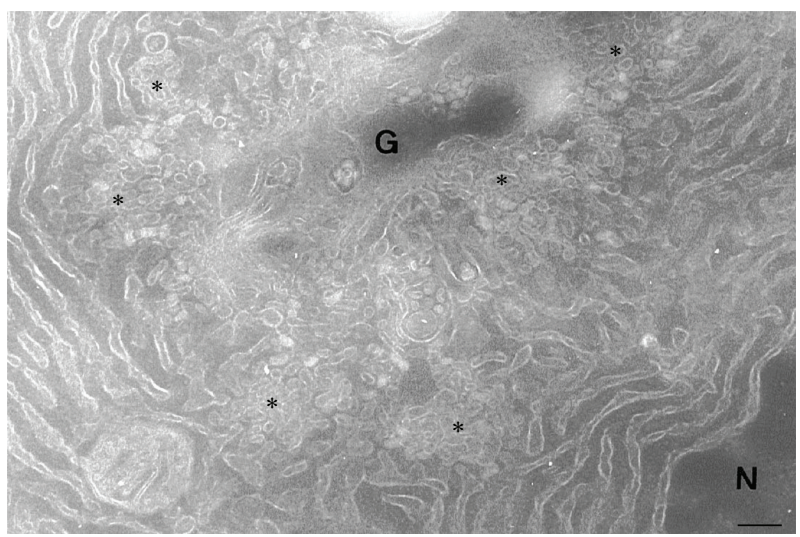

Figure 2: Cryosection of the Golgi complex of a rat exocrine pancreatic cell. Face view of a single cisterna $(G)$ showing the huge complexity of the surrounding tubulovesicular elements (asterisk). Without a detailed immunocytochemical analysis of their composition and high-resolution structural study, it is not possible to discern whether these membranes represent the ERGIC, CGN, peri-Golgi vesicles, or tubules connecting the stacks laterally. $\mathrm{N}=$ nucleus. $\mathrm{Bar}=$ $200 \mathrm{~nm}$.

these organelles [28]. The primary role of the stack is the glycosylation of proteins and lipids. In the GC, there are glycosidases, nucleotides sugar transporters, and at least 200 different glycosyltransferases [37], few of which are homogeneously distributed through the Golgi stack. For example, enzymes associated with early and late steps of glycosylation are predominantly found at the cis and trans sides, respectively. Peptide-GalNAc-transferase and GlcNAcphosphotransferase are associated with the cis Golgi, mannosidase I and II, GlcNAc transferase I and phosphodiesterase to the medial Golgi, and $\beta$-1,4-galactosyltransferase and $\alpha-2,6$-sialyltransferase to the trans side [38]. Most proteins associated with the Golgi function (matrix proteins, Rabs, SNARE, etc) also show a polarized distribution. There is also a cis-trans gradient of cholesterol and sphingolipids [39, 40]. The retention of transmembrane proteins within Golgi membranes depends on protein-protein interactions, the composition and length of the transmembrane domain and cytoplasmic tail, the lipid environment, and their binding affinity to coat complexes, whereas the localization of peripheral membrane proteins depends on protein-protein interaction and the posttranslational addition of lipids [41]. It should be noted that such polarization is not strict but, rather, proteins show a gradient-like distribution suggesting a dynamic equilibrium. Supporting this concept, the location of $\mathrm{N}$-acetylgalactosaminyl transferase, the enzyme that initiates $\mathrm{O}$-glycosylation, is regulated by growth factors that can induce its redistribution to the ER [42].

Associated to the cis Golgi side of the Golgi stack, there is a tubulovesicular system known as the cis-Golgi network (CGN). This is formed of tubules connected to the first Golgi cisterna [43-46], a cisterna containing many fenestrations [28]. In early electron microscopical studies, these tubules were selectively stained with reducing osmic for prolonged times. The boundaries and the functional relationship of this 
tubular network connected to the stack and ER-derived preGolgi tubule-vesicular elements (see below) remain to be established.

The trans-Golgi network (TGN) is located at the trans side and is the place where proteins are sorted, packed, and delivered to their final destination (endolysosomal system, apical or basolateral membranes, secretion). It is also the compartment where secretory and endocytic routes converge [47]. In the TGN the final steps of glycosylation (including sulfation and sialylation), serine-linked O-phosphorylation, and the proteolytic processing of hormone precursors take place. The organization of these membranes depends on cell type. Usually the TGN is formed by a network of tubulovesicular membranes connected to one or two transmost cisternae, while secretory cells, containing immature secretory granules. However, the TGN may be an independent compartment adjacent to the stack or, conversely, at some distance from the same [48-51]. The tubular component is extensive in cells with a well-developed lysosomal system and reduced in secretory cells. The structural variability of the TGN may be due to its capacity to secrete different types of cargo [52], and it is not clear whether this compartment is divided into subdomains representing specialized exit sites for different destinations [22, 53, 54]. Although functionally and structurally connected, the TGN and Golgi stack are different compartments, as demonstrated in the use of brefeldin $\mathrm{A}$. This fungal drug induces the tubulation of both compartments but fusion with the endosomal system or ER, respectively [55]. The $\mathrm{pH}$ of the TGN is more acidic than the medial/trans cisternae (6.58 and 5.91, resp.) [56].

The structure of the GC is supported by the so-called Golgi matrix, a ribosome-free area surrounding the cisternae and formed by structural proteins. This matrix is visualized by electron microscopy as small fibers connecting the cisternae [57] and also connecting the Golgi membranes and transport vesicles [58]. A large number of Golgi matrix components have been identified, including Golgi reassembly stacking proteins (GRASPs) and golgins [59], with GM130 being the first component identified [60]. Some of the components were identified as autoantigens and others were isolated from detergent-insoluble salt-resistant Golgi fractions [61]. These components are very dynamic and cycle between membraneassociated and a cytoplasmic forms, process that depends on posttranslational modifications such as phosphorylation. Matrix proteins are involved in the regulation of membrane traffic and the maintenance of the Golgi structure. More recently, the matrix has been related to microtubule organization, signaling, and regulation of apoptosis and cell cycle [59].

The organization of the Golgi ribbon also depends on the microtubule and actin cytoskeleton $[62,63]$. In nonpolarized cells, stacks are distributed around the microtubule organization center (MTOC), usually close to the nucleus $[64,65]$. However, microtubules are not essential for other functions such as glycosylation or global secretion. The final position of the ribbon and transport into or from this organelle is determined by the action of molecular motors. The movement of transport carriers from the periphery to the GC at the cell centre is mediated by the minus-end-directed motor dynein. This motor and its cofactor, dynactin, are essential for maintenance of the perinuclear position of the Golgi ribbon [66]. The movement in the opposite direction is mediated by the plus-ended-directed motor kinesin. Interestingly, the GC is able to nucleate and stabilize microtubules acting as a secondary MTOC [67]. The cis-Golgi protein GMAP210 recruits $\gamma$-tubulin to this organelle. AKAP450, a $\gamma$ tubulin-interaction centrosomal protein, is also found at the Golgi, after recruitment by GM130 [68]. At the trans-Golgi, the nucleation of microtubules depends on microtubulebinding proteins, CLASPs, which are recruited to the Golgi membranes through the golgin GCC185 [69]. This process is necessary for polarized secretion and the maintenance of the Golgi ribbon [70]. On the other hand, actin has been associated with coated transport vesicles and buds [71]. Golgi membranes also contain molecules, such as Arp2/3, N-WASP, or cdc42, that trigger actin polymerization [72]. Actin filaments and actin-associated proteins are involved in post-Golgi [73] and Golgi-to-ER [74] transport. Interestingly, the action of the microtubule and actin cytoskeletons is coordinated [75]. One of the factors involved in this link is the protein WHAMM (WASP homology associated with actin, membrane, and microtubules), which is present in the Golgi and pre-Golgi elements. This protein has domains that bind actin-binding proteins, such as profilin and Arp2/3, a domain that directly bind microtubules and a domain required to bind lipids [76]. WHAMM regulates carrier morphology during intracellular transport [77].

\section{Transport Carriers: Vesicles}

The stacks are surrounded by small vesicles of different sizes and many of them are coated. For example, in two adjacent stacks of NRK cells, of the $\sim 400$ vesicles found, one half were coated [28]. Three different types of coat complexes have been identified and characterized in detail (COPI, COPII, clathrin), although the existence of other coat complexes cannot be rejected.

Clathrin-coated vesicles were the first to be identified [78, 79]. Both their size $(100 \mathrm{~nm})$ and the coat thickness (18 nm) are larger than in COP vesicles [80]. Clathrin is mainly involved in transport from GC or from the plasma membrane to the endolysosomal system [81]. In the Golgi area, clathrincoated vesicles and buds are associated with the trans-most Golgi cisterna and TGN [28], where it is involved in the export of mannose-6-phosphate receptors carrying newly synthesized lysosomal enzymes [82]. Clathrin is a protein complex formed by three heavy and three light chains that assemble to make a basket-like structure, made up of pentagons and hexagons [83]. Their association with membranes and the recruitment of cargo is mediated by adaptor complexes. Clathrin binds a variety of adaptor complexes involved in different transport events. In humans, four ubiquitously expressed adaptor complexes (AP1-4) and three Golgilocalized $\gamma$-ear-containing ARF-binding proteins (GGA1-3) have been identified. AP2 is restricted to the plasma membrane, where it is involved in endocytosis, whereas GGAs and AP1-4 are located at the TGN and/or in endosomes [17]. At the TGN, AP1, and CGA proteins recognize specific signals 
present in mannose-6-phosphate receptors and contribute to the sorting of these receptors, which their cargo hydrolyses into clathrin-coated vesicles [82]. AP1, AP3, and AP4 (in this case independently of clathrin) are involved in the sorting of lysosomal membrane proteins at the TGN. In polarized cells, AP1, AP3, and AP4 are involved in the sorting of basolateral membrane proteins, but probably through a clathrinindependent mechanism [84]. The binding of cargo and adaptor recruits clathrin, which provides the scaffold for the invagination of the membrane forming a coated pit. Fission of the vesicle requires the activity of the GTPase dynamin [85], whereas vesicle uncoating depends on recruitment of the chaperone Hsc70 by the nerve-specific auxilin or the ubiquitous GAK [86].

COPII- and COPI-coated vesicles are morphologically very similar. They are $50-60 \mathrm{~nm}$ in diameter with a $10 \mathrm{~nm}$ thick coat. However, their composition, location, and role in transport differ. The COPII coat is formed of five proteins: Sec23, Sec24, Sec13, Sec 31, and the GTPase Sar1 [87, 88]. These proteins are soluble in the cytosol but associated to form coated buds at the ER. Sarl is the first component recruited in ER membranes. This binding depends on the activation of this GTPase by Sec12, a guanine nucleotide exchange factor (GEF) present in ER membranes [89]. Sar1 recruits the Sec23/Sec24 heterodimer and then the Sec13/ Sec31 complex [90]. During this process some proteins are selectively recruited in COPII vesicles [91], whereas others enter unspecifically, a process known as bulk flow [92]. The size of the COPII vesicles can be adapted to a bulky cargo. TANGO 1 is an adaptor protein that helps collagen VII to enter into vesicles [93]. Recently, it has been shown that ubiquitination of Sec31 regulated the formation of large COPII vesicles [94]. The role of COPII in ER-to-Golgi transport is well established. In specific places of the ER, the ER exit sites, this coat complex drives the formation of free coated vesicles containing cargo. These are quickly uncoated and fuse to each other to form the so-called endoplasmic reticulum-Golgi intermediate compartment (ERGIC) or vesicular-tubular aggregates (VTCs) [95]. This compartment is formed of tubulovesicular elements located close to the GC and distributed throughout the cell, and is associated to ER exit sites [96]. This compartment was initially identified because the cargo accumulated in these elements when cells are cultured at low temperature $\left(15^{\circ} \mathrm{C}\right)[97,98]$. At the ERGIC, the COPI coat mediates the recycling of proteins back to the ER, while anterograde cargo is separated and concentrated. It is not clear whether the ERGIC is a stable and static compartment or, conversely, whether it works as a carrier [99]. The fact that the proteins associated with this compartment are not resident but cycling between the ER and Golgi argues against the idea that it is a stable compartment. This is the case with ERGIC-53, a type I transmembrane protein of the lectin family, which is the prototypical marker of this compartment [100]. Anyway, ERGIC elements or ERGIC-derived carriers move to the Golgi area along the microtubule track and, there, they may fuse to each other to form the CGN or, conversely, fuse with a preexisting cisterna [101].

COPI-coated vesicles are found in peripheral and central ERGIC elements, cis and lateral Golgi sides [80] and, occasionally, at the trans-Golgi side/TGN [102]. COPI-coated buds are observed at the lateral rims of cisternae, decreasing in number in a cis to trans direction [28]. COPI and clathrincoated areas have been observed in immature secretory granules [92]. The function of the COPI coat in the Golgito-ER retrograde transport of soluble and membrane proteins has been convincingly demonstrated [103]. However, there are retrograde routes to the ER independent of COPI [104]. COPI has also been associated with the anterograde and retrograde intra-Golgi transport of cargo and resident enzymes, respectively, although this role remains highly controversial (see below). COPI coats are also involved in Golgi fragmentation during mitosis, Golgi positioning, lipid homeostasis, and endocytic routes [105]. It is possible that there are several subpopulations of COPI vesicles with different compositions and locations, each carrying out its specific functions [106]. The discovery and characterization of COPI vesicles data from the early 1980s when transport intermediates were analyzed in cell-free experiments, incubating Golgienriched membranes with cytosol and GTP $\gamma \mathrm{S}[107,108]$. COPI coats are formed of seven subunits $\left(\alpha, \beta, \beta^{\prime}, \gamma, \delta, \varepsilon\right.$, $\zeta$-COP) assembled in the cytosol, where they form a complex named coatomer [109] and the small GTPase ARF1 [110]. ARF1 cycles between GDP- and GTP-bound forms [111]. GTP-bound ARF1 binds to membranes and recruits the coatomer en bloc, resulting in membrane deformation. Like all small GTPases, the activity of ARF1 is regulated by guanine nucleotide exchange factors (GEPs) and GTPase-activating protein (GAP). GEF catalyzes the exchange of GDP with GTP. Golgi-associated BFA-resistant protein (GBF1) is the major GEF for ARF1 during COPI vesicle formation in the Golgi membranes and is the target of the drug brefeldin A $[112,113]$. Brefeldin A blocks the ARF1-GEF complex inhibiting the formation of ARF1-GTP and triggering Golgi disassembly. ARFGAP proteins stimulate the GTP hydrolysis of ARF, which has low intrinsic GTPase activity [114]. It has been postulated that this reaction triggers uncoating [115], but this point is under discussion [116]. The proteins BARS and endophilinB seem to be necessary for the fission of COPI vesicles. Interestingly, ARFs have a role in the recruitment and activation of lipid-modifying enzymes. In addition, ARFGAP1, the first identified GAP for ARF1, is a membrane curvature sensor [117]. Cargo inclusion requires GTP hydrolysis [118]. For cargo sorting, coatomer recognizes dibasic sequences $[105,119]$. Many transmembrane proteins transported into COPI vesicles bear dilysine motifs at their Cterminus [120], including ERGIC-53 [121]. The coatomer subunits, $\alpha$ - and $\beta^{\prime}$-COP, bind this signal directly [122]. The p24 family of proteins (23-24 kD transmembrane proteins) are recruited by direct interaction of their cytoplasmic tail which contains phenylalanine- and dilysine-based signals, to coatomer [123]. However, not all cargo incorporated in COPI vesicles have this sorting signal and may require adaptors. One example is the KDEL receptor, a transmembrane protein mostly present in the cis Golgi and ERGIC that works as an adaptor for soluble proteins. It interacts with the coatomer through a dilysine motif in the cytosolic tail whereas the luminal part interacts with soluble proteins bearing a K-DE-L sequence (HDEL in yeast), a sequence found in many 
ER-resident proteins $[124,125]$. In this way, soluble proteins that have escaped from the ER are retrieved. Glycosylation enzymes may also require cargo adaptors [105].

\section{Transport Carriers: Tubules and Heterogenic Elements}

For a long time, it was assumed that membrane traffic is mediated by coated vesicles. Although they play a key role in many steps of the transport, it is possible that coated vesicles just represent a fraction of the intermediate transport carriers operating in the secretory pathway [126]. Tubular elements, on the other hand, have been associated with all steps of the secretory pathway (Polishchuk and Mironov [52]). The transport of soluble [127] and transmembrane [99] cargo from pre-Golgi elements to the Golgi is mediated by tubules. Tubules are $20 \%$ of the elements operating at the ER-Golgi interface [128]. Post-Golgi carriers may also have a tubular form $[129,130]$. In fact, the TGN itself is often formed by a network of branching tubules.

Tubules are also involved in intra-Golgi transport. The GC is associated to an extensive network of $30 \mathrm{~nm}$-thick tubules connected to the lateral edges of the stacked cisternae and may extend a considerable distance from the stacks [57]. Golgi tubules were already observed in the first electron microscopical observations of this organelle [25]. Early studies showed tubular elements emerging from the Golgi stack and TGN, connected to cisternae or oriented towards the cytoplasm [26, 27]. Hermo and coworkers [131] described tubular connections between cisternae in the cis side of the Golgi apparatus of spermatids. Despite this, tubules were almost forgotten in the field for decades probably due to the difficulty of identifying them in bidimensional electron micrographs (they only can be identified in longitudinal sections). This was exacerbated cisternal maturation model being abandoned in favor of the vesicular transport model. Research into these elements increased with the introduction of the drug brefeldin A in the study of the GC. This drug induces extensive tubulation of this organelle. Although this system is artificial, it has been postulated that brefeldin A exaggerates the natural process of retrograde transport. However, in contrast with normal conditions, this transport occurs only after the dissociation of COPI coats from the GC. The development of new methodologies, such as timelapse confocal microscopy or electron tomography, has reintroduced the idea that tubules are transport intermediates. Time-lapse analysis of living cells has shown tubules emerging from the GC [132] containing GFP-tagged resident enzymes [133] or cargo [101, 134]. Electron tomography confirms that these elements are commonly associated to the GC $[28,135]$. In NRK cells, there are tubules that emerge from cis and trans cisternae, suggesting that they are involved in incoming and outgoing Golgi trafficking. Tubules may grow from all cisternae and may extend towards CGN and TGN. Interestingly, one single cisterna may contain tubules oriented to both cis and trans faces [28]. In cells stimulated to increase the secretion rate, tubular connections between cisternae are evident [136, 137], but these connections disappear when cargo has left the GC. Thus, tubules might replace vesicles when there is an excess of cargo. Tubules may also participate in the recycling of Golgi resident enzymes. Under low temperature $\left(15^{\circ} \mathrm{C}\right)$ conditions, many tubules emerge from the GC of HeLa cells. These tubules are enriched in Golgi-resident enzymes and a specific set of SNARE and $\mathrm{Rab}$ proteins associated with intra-Golgi transport and contain neither retrograde nor anterograde cargo [138, 139]. This type of tubule can also be observed under physiological conditions and they are good candidates for being considered transport intermediates at the Golgi level. Several types of tubules with different functions may well exist.

The molecular machinery involved in the formation of Golgi tubules is just beginning to be known. Based on brefeldin A experiments, tubular formation at the GC has been related with the loss of COPI coats [140, 141]. GTPbound ARF1 is able to induce Golgi tubules by insertion of the amino-terminal amphipathic helix [142]. Microtubuleassociated motor proteins are sufficient to induce tubules from Golgi membranes [143]. Some lipidic species, such as phosphatidic acid, diacylglycerol, and lysophosphatidic acid, favor the curvature of membranes. Thus, enzymes associated with lipid metabolism play a key role in tubular formation. Lysophosphatidic acid generated by the enzyme phospholipase A2 has been involved in the retrograde transport mediated by tubules $[144,145]$. Agonist and antagonist of this enzyme increase or inhibit tubular formation, respectively. This enzyme is involved in the formation of tubular continuities between cisternae [146] and tubular transport intermediates at the TGN [147]. The formation of transport carriers at the TGN is also diacylglycerol dependent. This lipid is necessary to recruit protein kinase $\mathrm{D}$, a regulator of the fission of transport carriers [54, 148]. Diacylglycerol has also been involved in Golgi-to-ER retrograde transport mediated by tubules [149]. Phosphatidic acid has been involved in intraGolgi transport [150]. Interestingly, two lipid-modifying enzymes, lysophosphatidic acid acyltransferase- $\gamma$ and phospholipase A2- $\alpha$ which promote or inhibit COPI fission, respectively, work together, regulating the morphology of Golgi carriers [151]. On the other hand, the morphology of pre-Golgi tubules depends on the cargo [128], COPI coats, microtubules, and associated motor proteins [152], and also the activity of ARF and phospholipase A2 [153]. Thus, similar machineries may be operating at different levels of the secretory pathway. Interestingly, live cell imaging shows that preGolgi elements may change their morphology very quickly from vesicular to tubular form and vice versa [152].

Apart from the tubules, other transport intermediates of heterogeneous morphology have been described. Polishchuk and coworkers [154] described the formation of large tubulosaccular elements involved in the microtubule-dependent transport from the TGN to the plasma membrane. The same group has described heterogenic membranes involved in ERto-Golgi transport [155]. Very large pleiomorphic membranebound elements have also been associated with transport in the early secretory pathway [156]. It seems that there are different classes of transport carriers depending of the amount or type of cargo. 


\section{Molecular Machinery}

In recent decades, a huge amount of information has been accumulated about the molecular machinery involved in the regulation of the intercompartmental transport in the secretory pathway. Most data refer to vesicles as transport carriers but it can be assumed that the same or similar mechanisms operate for other carriers. If the formation of vesicles and the selection of cargo depends on the coat machinery, the specific targeting and fusion of the carriers with the target membranes depends on tethering factors, Rab and SNARE proteins, and other accessory proteins [157]. In a simple model, the rabs on incoming vesicles recruit tethering factors which permits SNARE complex formation.

SNAREs (soluble N-ethylmaleimide-sensitive factor attachment proteins receptors) proteins are involved in docking and the specific fusion of transport intermediates with the target membranes [157-159]. The SNAREs associated with vesicles (or other transport intermediates) and target membranes have been named $\mathrm{v}$ - and t-SNARE, respectively. This terminology, however, is not useful for describing homotypic fusion events. Structurally, SNAREs have been divided into R- and Q-SNAREs according to the central residue (R/Gln or $\mathrm{Q} / \mathrm{Arg}$, resp.) of the SNARE domain, a conserved region of 60-70 residues found in all members of this family. Although there are some exceptions, v-SNARE and t-SNARE are R-SNARE and Q-SNARE, respectively. Interaction between one v-SNARE and two/three t-SNARE induces the formation of the trans-SNARE complex which catalyzes the fusion of the membranes. SNARE proteins are sufficient to drive membrane fusion so that they are considered the minimal membrane fusion machinery. After fusion, a cis-SNARE complex is formed in the target membranes. This complex is later disassembled by the action of the cytosolic proteins $\alpha$-SNAP (soluble N-ethylmaleimidesensitive factor attachment protein) and the ATPase NSF (N-ethylmaleimide-sensitive factor). Now, v-SNARE can be transported back to the donor compartment to be reused. Several SNARE complexes working at the secretory/endocytic pathway have been identified. In mammalian cells, two SNARE complexes have been implicated in intra-Golgi transport [160]. A complex is formed of v-SNARE GS15 and the t-SNAREs syntaxin5, GOS28 and Ykt6, is involved in COPI-dependent intra-Golgi transport. The second complex is formed of syntaxin 5, membrin (GS27), ERS24/Sec22, and rBetl, the last one acting as v-SNARE. This second complex has been also involved in the fusion ER-derived elements with the cis-Golgi and possible intra-Golgi transport. The distribution of these SNAREs across the Golgi stack is different. Thus, in general, the components of the first complex increase in concentration toward the trans side, whereas the components of the second complex decrease [161], supporting the idea that these complexes mediate transport events in opposite directions. Syntaxin 5, which is present in both complexes, is distributed homogeneously through the stack. SNARE complex assembly is regulated by SM (Sec1/ Munc18) proteins, a family of cytosolic proteins. Slyl I is the only member of this family operating at the ER-Golgi area, where it interacts with syntaxin 5 and syntaxin 18 , at the Golgi and ER, respectively, and controls anterograde and retrograde transport between these compartments [162].

Rab proteins are a family of small GTPases regulating membrane transport by recruiting effector proteins $[159,163]$. They are localized at the cytoplasmic face of secretory and endocytic compartments and carriers, and they have been implicated in vesicle budding, uncoating, mobility and transport. Rab switches between an active form (GTP-bound) and a cytosolic inactive form (GDP-bound). Rab proteins in the GTP-bound form are reversibly associated with membranes by geranylgeranyl groups, recruiting a variety of effectors, including sorting adaptors, tethering factors, kinases, phosphatases, and motor proteins [163]. The replacement of GDP by GTP is facilitated by guanine nucleotide exchange factors (GEFs), and their low intrinsic GTPase activity is enhanced by GTPase-activating proteins (GAP). Further regulation of the GTP/GDP state and membrane association is provided by GDP dissociation inhibitor (GDI) and GDI displacement factors (GDFs). Rab protein is a large family, including more than 60 members in humans and 11 in yeast, which are specifically associated with distinct compartments and transport events [163]. Thus, Rab proteins have also been associated with the control of membrane identity by controlling local levels of phosphoinositides, which, concomitantly, may recruit specific proteins to certain compartments [164]. The association of Rab proteins with specific membranes is guided by Rab escort protein (REP) which presents newly synthesized Rab to geranylgeranyl transferase before targeting the membranes. The Golgi-associated Rab family playing a key role in Golgi maintenance and functioning includes Rab1, Rab2, Rab6, Rab33B, Rab18, and Rab43 [165]. Rab1 and Rab2 are involved in ER-to-Golgi transport. Rab 1 is also very important for Golgi ribbon maintenance. Interestingly, the levels of expression or the distribution of this small GTPase is affected in neurological disorders that show fragmentation of the Golgi ribbon [166] (Rendón et al. [167]). Rab6, and more specifically the Rab6A/A' isoform, is the most widely studied Golgi-associated Rab protein [168]. It is important for maintaining Golgi structure and also for regulating transport in and out of the GC, including a COPI-independent Golgito-ER transport [169]. It is also associated with post-Golgi carriers where it recruits motor proteins $[170,171]$ and also regulates the docking and fusion with the plasma membrane [172]. At the Golgi stack, it anchors the tethering factors necessary for attaching incoming vesicles. The organization of the Golgi ribbon, the regulation of the number of cisternae in the stack and transport of coated vesicles is also associated with Rab6 and effectors [173]. Rab33B is localized specifically in the medial Golgi [174], where it is involved in Golgi-toER retrograde transport [175]. Interestingly, Rab6A recruits specific GEF that also interacts with Rab33B connecting these Rabs in a Rab cascade [176]. Most probably, Rab6 and Rab33B work together in the regulation of intra-Golgi and Golgi-toER transport [165]. Less information is available about Rab43 and Rab18 but they are also thought to be involved in ERGolgi trafficking and Golgi organization.

Tethering factors are a group of membrane-associated proteins or multisubunit complexes that link transport vesicles with the target membranes to ensure correct docking and 
fusion. They have recently been classified into three classes: oligomeric complexes that work as Rab effectors and binds SNARE, oligomeric complexes that function as GEFs for Rab proteins and, finally, coiled-coil tethers [177]. Proteins with extensive coiled-coil domains are long, allowing long distance tethering. These bridges not only facilitate the formation of SNARE complexes, but also may provide an initial specificity for membrane fusion. Members of this family associated with the Golgi are called golgins [178]. In addition to tethering, they have a role in Golgi stacking and form the Golgi matrix. This family includes p115 and GM130, the first of which is associated with COPI and COPII vesicles, the ERGIC, and cis-Golgi membranes. This protein is believed to be involved in tethering of COPII vesicles to ERGIC membranes and the transport events from these elements to the cis-Golgi. It is also possible that it participates in transport between cisternae. The recruitment of pl15 to membranes is Rabl dependent. It also interacts with ER-Golgi SNAREs, COG subunits, and other coiled-coil proteins such as GM130 and giantin. The significance of the last interaction is not clear. GM130 is another coiled-coil protein associated with the cis Golgi. It interacts with many proteins including GRASP65, p115, Rab1, Rab2, Rab33b, and sintaxin5. P115 and GM130 are members of the family of golgins, which were first identified as Golgilocalized autoantigens using antibodies derived from the sera of patients with a variety of autoimmune disorders. As indicated above, GM130 and p115 are also components of the Golgi matrix. Apart from their role as tethers, together with other members of the golgin family such as GRASP65 and giantin, they are involved in maintaining the stacked morphology of the cisterna and the Golgi ribbon [179].

Multisubunit complexes associated with the Golgi include Dsl1, COG, and TRAPPI/II [177]. Dsll is a three-unit complex involved in Golgi-to-ER transport, where it acts as tethering COPI vesicles. It interacts and stabilizes an SNARE complex at the ER. The conserved oligomeric Golgi (COG) complex formed of 8 subunits (Cog1-8) found at the cis- and medial Golgi cisternae is believed to be involved in transport to the Golgi and intra-Golgi recycling of Golgi resident proteins [180]. Components of this tethering factor interact with COPI components, SNARE proteins (syntaxin 5), and coiled-coil tether (p115), and are the effectors of several Rab proteins (Rab1, Rab6). Transport protein particle (TRAPP) is another multisubunit complex that works as tethering factor [181]. Two complexes have been identified, TRAPP I and TRAPPII, which are involved in entry and exit from the GC, tethering COPII, and COPI vesicles, respectively. They work as GEF for Rabl and the activation of this GTPase might recruit other tethers (as p115 or COG) [177]. However they do not interact directly with SNAREs. It is possible that there is a cascade of tethering factors that facilitates cargo transport.

\section{Intra-Golgi Transport}

The mode of transport across the GC remains controversial. Two main models have been proposed: vesicular transport and cisternal maturation. The first one proposes that Golgi cisternae are static so that the cargo must move via vesicles. The second model support that cisterna are dynamic structures that move from the cis to trans Golgi side. Thus, according to this model, the entire cisterna is the carrier. In these models, COPI-coated vesicles are responsible for anterograde and retrograde transport, respectively (Figure 3 ). Since neither of these models explains all the experimental data, a combination of the same models and new models have been proposed (see below).

6.1. Vesicular Transport Model. This model was launched by Palade in 1975 and was widely accepted for many years because it provides a good explanation for the well-known compartmentalization of the Golgi resident enzymes. In this model, it is assumed that cisternae are stable compartments so that the cargo must leave one cisterna and move to the next in order to advance through the stack. This process is mediated by vesicles. The model was strongly supported by the discovery of COPI and COPII vesicles [182]. COPI were identified in in vitro assays as being responsible for anterograde transport between cisterna [107]. In these cell-free experiments, when the formation of COPI was inhibited, anterograde was blocked $[183,184]$. On the other hand, it was clearly demonstrated that COPII vesicles are involved in ER exit and transport to the GC [87]. Soon it was assumed that COPII and COPI vesicles act sequentially in the early secretory pathway, that is, ER-to-Golgi and intra-Golgi transport, respectively. However, new experimental data cast doubt on the model. First of all, a clear role of COPI vesicles in retrograde transport was demonstrated $[120,185]$. To fit these data with the model, it was postulated that there were two types of COPI vesicles involved in anterograde and retrograde transport at the Golgi stack [186]. "Percolating" COPI vesicles may move bidirectionally up and down in the stack in a random way but allowing a net rate of flow of anterograde cargo in the cis-to-trans direction [187]. However, immunocytochemical [188] and proteomic [9] analysis of these vesicles showed that they are mostly devoid of anterograde transport markers. Thus, the role of COPI vesicles remains controversial [189]. The small number of Golgi-associated SNARE and Rab proteins also argues against multiple fusion events between vesicles and every cisterna in the stacks. One problem is that this model does not explain the transport of large cargo, such as procollagen (300 $\mathrm{nm}$ rigid rod) [190] or algal scales (up to $1.5-2 \mu \mathrm{m}$ ) [191], within 50-60 nm vesicles. Interestingly, scales, which are electron dense and can be easily visualized, are not observed within vesicles. The existence of megavesicles transporting large $(>400 \mathrm{~nm})$ protein aggregates has been described in an artificial system [192] but it is not clear that this a general mechanism used by nonmodified cells [190].

6.2. Cisternal Maturation Model. This model was postulated in the early époque of electron microscopy [193] and updated as cisternal progression-maturation model [190, 194]. According to this model, cisternae are formed at the cis side of the GC by fusion of ER-derived membranes and then, these newly formed membranes move from the cis to 

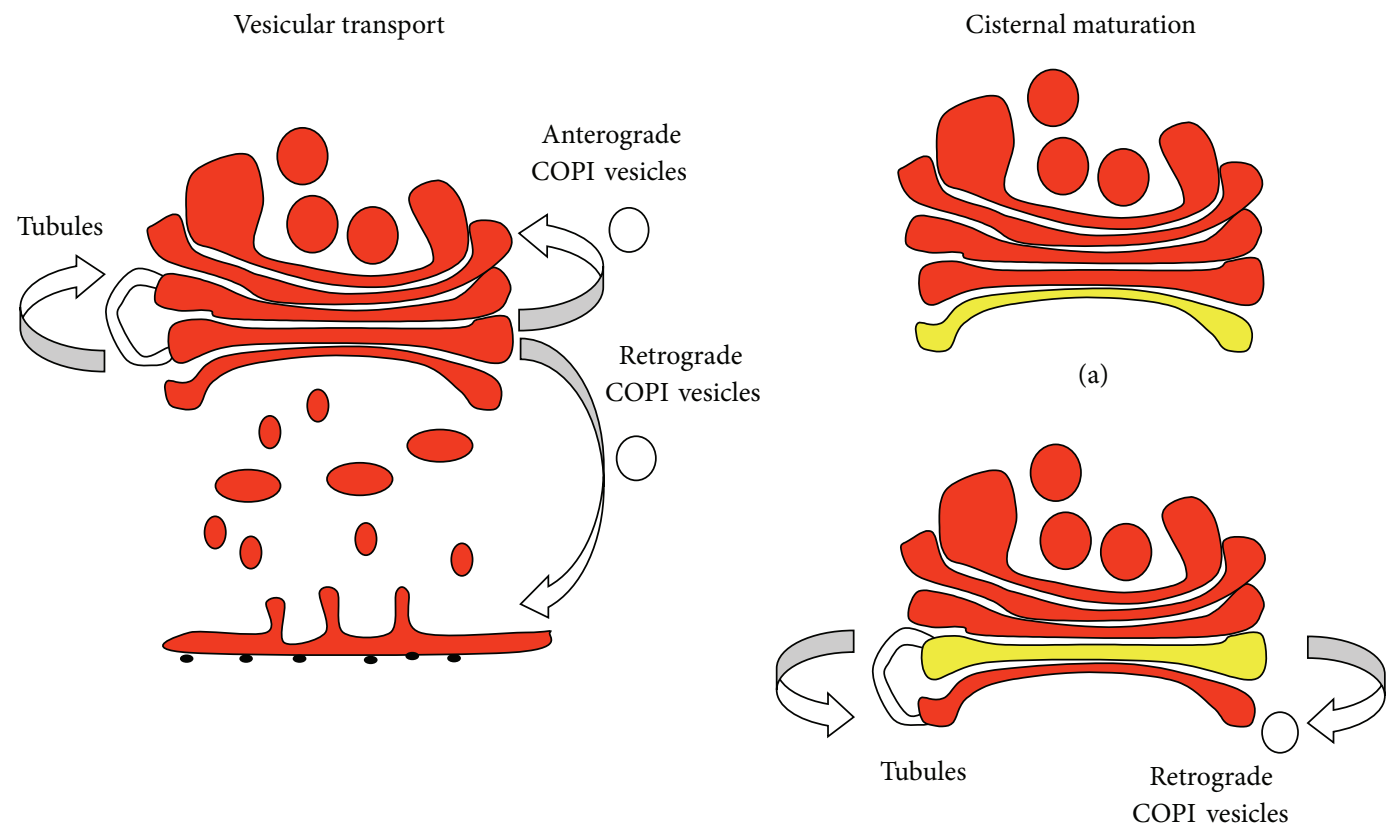

(b)

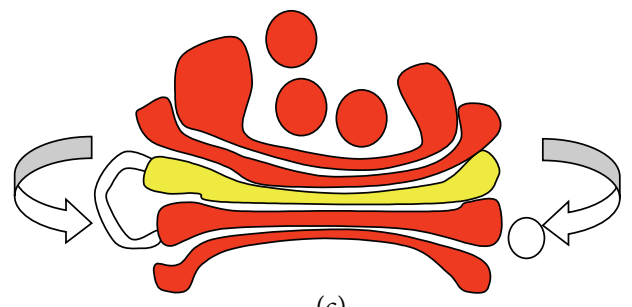

(c)

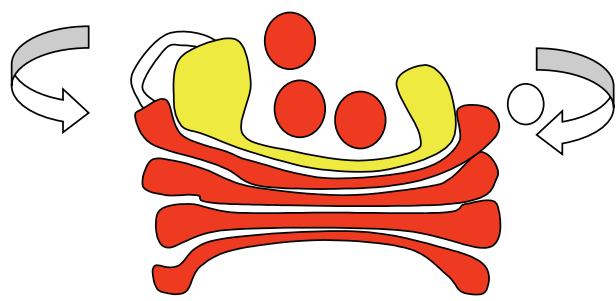

(d)

FIGURE 3: Putative role of COPI-coated vesicles and tubules according to vesicular transport and cisternal maturation models for intra-Golgi transport. According to vesicular transport model, cisternae are static. Anterograde transport may be mediated by COPI-coated vesicles and tubular cisternal connections. Another type of COPI-coated vesicles mediates retrograde transport (i.e., the retrieval of proteins that have escaped from the endoplasmic reticulum). According to cisternal maturation model, cisternae move from cis (a) to trans Golgi sides (d). COPI-coated vesicles and transient tubules may be involved in the recycling of Golgi resident proteins (retrograde transport).

the trans side, where they become post-Golgi carriers. Thus, newly formed cisterna gradually displaces older cisternae towards the trans side. In this model, it is not necessary for the cargo to leave the cisterna and the whole cisterna is taken to act as a carrier. This model explains the transport of large cargo and an analysis of procollagen transport fits this model very well [190]. These large molecules are detected in large distensions at the lateral edge of the cisterna in their transit through the stack. These distensions are always connected to the cisterna so that procollagen is not transported by large vesicles. In contrast, the model does not explain the polarity of the stack and what happens with resident enzymes when cisternae disappear at the trans side. To overcome these problems, it was assumed that Golgi resident enzymes are packed into COPI vesicles during cisternal progression and transported backwards. Thus, Golgi enzymes are not lost but recycled in a trans-to-cis direction, maintaining the polarity of this organelle [195]. The cisternae mature by 
acquiring and then losing specific Golgi-resident proteins. The presence of Golgi resident enzymes in COPI vesicles has been demonstrated [188] although their relative concentration is controversial. Life cell imaging studies in yeast strongly support this model. In Saccharomyces cerevisiae, the Golgi is not stacked, so that individual cisterna can be analyzed separately. Using cis and trans Golgi markers it was directly demonstrated that cisternae mature (i.e., the apparently conversion of one type of cisterna into another) [196, 197]. The cisternal maturation model seems to be more efficient given that it would seem easier to transport anterograde cargo using a large carrier (the cisterna) than to use many small vesicles between adjacent cisternae and repeating this process several times until reaching the TGN. It is also intuitive that peri-Golgi vesicles should be restricted to more selective and smaller trafficking, the retrograde pathway.

6.3. Alternative Models. Given that none of these models completely explains all the experimental data, new models have been postulated, although some of them are variations of the two main models.

Dual transport model: one possibility is that these two models are not mutually exclusive but rather complementary and working simultaneously [198]. Cisternae may move slowly, whereas vesicles transport anterograde and retrograde cargo more rapidly. Large molecules may use the cisternal maturation mechanism while small molecules can be transported using vesicular transport $[186,198]$.

Rapid partitioning model. This model is based on the rapid partitioning of transmembrane cargo and resident enzymes between two lipid phases. According to this model, the GC works as a single compartment but contains processing and export domains [199]. When the cargo reaches the Golgi, it associates with these domains and then leaves the compartment from every level. Again, this model has difficulty in explaining the polarity of the cisternae and does not help visualize the Golgi stack as a single compartment.

Kiss-and-run model. This model is based on mechanisms operating in other systems such as endosomes and lysosomes. This model proposes that two cisternae may fuse to each other through narrow tubules, connecting their lumens transiently, and allowing the transit of cargo before separating [200]. In this model, anterograde transport and retrograde transport occur simultaneously and a specific retrograde pathway is not necessary. This model may explain several aspects of Golgi transport, including the transport of large molecules. However, some assumptions of the model need to be confirmed (i.g. machinery and mechanisms for the fusion and fission of connections). It is also not clear how all the experimental data about the role of COPI coats in retrograde transport fit this model.

Intra-Golgi transport mediated by tubules. The absence of cargo in COPI vesicles suggests that other transport intermediates such as tubules may operate at the GC. As mentioned above, tubules are a common structure surrounding the stack. Tubules may be involved in the anterograde movement of cargo through this organelle. The ER and all cisternae may be directly connected by tubules and cargo might move along the secretory pathway like food through the gut [201]. In fact, conditions that stimulated protein secretion increase the number of tubular connections between cisternae [136, 137]. Conversely, tubules may establish transient connections between compartments, helping COPI vesicles to transport Golgi enzymes retrogradely as indicated by the cisternal maturation model [46] (Figure 3). Cisternal maturation in yeast occurs, although slowly, without COPI vesicles, suggesting that tubules may replace them [197]. Low temperatureinduced Golgi tubules are enriched in Golgi enzymes and SNARE and Rab proteins involved in intra-Golgi transport, whereas they exclude other proteins associated with ERGolgi transport [139]. Whether the tubules found in this model are representative of the carriers involved in intraGolgi transport remains to be established.

\section{Concluding Remarks}

A century after the discovery of the "apparato reticolare interno" [202], it is clear that no model for intra-Golgi transport explains all the experimental data. But it is also true that the "high polarity" that exits the field has stimulated intense research. Recently developed high-resolution methodologies may give important clues in this respect. Of special interest is the analysis of the structure and composition of tubular and vesicular carriers. High-resolution immunocytochemical techniques in combination with electron tomography, as well as proteomic analysis of highly purified samples, may solve the problem or at least definitively reject some models. In the end, it is possible that each cell type, depending of its special characteristics, uses a given mechanism of intra-Golgi transport. It also remains possible that a single cell uses different mechanisms of intra-Golgi transport, depending on the amount and type of cargo or its physiological status. Meanwhile cisternal maturation in combination with tubular transient connections is a very attractive and intuitive model that seems to fit most experimental data.

\section{Acknowledgments}

The work in this paper was supported by Grants from the Ministerio de Ciencia e Innovación (Spain) Consolider COAT (CSD2009-00016) and Fundación Séneca de la Comunidad Autónoma de la Región de Murcia (04542/GERM/06).

\section{References}

[1] G. Palade, "Intracellular aspects of the process of protein synthesis," Science, vol. 189, no. 4200, pp. 347-358, 1975.

[2] W. Nickel and C. Rabouille, "Mechanisms of regulated unconventional protein secretion," Nature Reviews Molecular Cell Biology, vol. 10, no. 2, pp. 148-155, 2009.

[3] M. G. Farquhar and G. E. Palade, "The Golgi apparatus (complex) (1954-1981) from artifact to center stage," Journal of Cell Biology, vol. 91, no. 3, pp. 77s-103s, 1981.

[4] M. G. Farquhar and G. E. Palade, "The Golgi apparatus: 100 years of progress and controversy," Trends in Cell Biology, vol. 8, no. 1, pp. 2-10, 1998. 
[5] C. Wilson, R. Venditti, L. R. Rega, A. Colanzi, G. D’Angelo, and M. A. De, "The Golgi apparatus: an organelle with multiple complex functions," Biochemical Journal, vol. 433, no. 1, pp. 1-9, 2011.

[6] J. Lippincott-Schwartz, E. Snapp, and A. Kemvorthy, "Studying protein dynamics in living cells," Nature Reviews Molecular Cell Biology, vol. 2, no. 6, pp. 444-456, 2001.

[7] G. Perinetti, T. Müller, A. Spaar, R. Polishchuk, A. Luini, and A. Egner, "Correlation of $4 \mathrm{Pi}$ and electron microscopy to study transport through single golgi stacks in living cells with super resolution," Traffic, vol. 10, no. 4, pp. 379-391, 2009.

[8] J. Lippincott-Schwartz, "Emerging in vivo analyses of cell function using fluorescence imaging," Annual Review of Biochemistry, vol. 80, pp. 327-332, 2011.

[9] A. Gilchrist, C. E. Au, J. Hiding et al., "Quantitative proteomics analysis of the secretory pathway," Cell, vol. 127, no. 6, pp. 12651281, 2006.

[10] J. Gannon, J. J. Bergeron, and T. Nilsson, "Golgi and related vesicle proteomics: simplify to identify," Cold Spring Harbor Perspectives in Biology, vol. 3, no. 12, 2011.

[11] F. Bard, L. Casano, A. Mallabiabarrena et al., "Functional genomics reveals genes involved in protein secretion and Golgi organization," Nature, vol. 439, pp. 604-607, 2006.

[12] J. W. Slot and H. J. Geuze, "Immunoelectron microscopic exploration of the Golgi complex," Journal of Histochemistry and Cytochemistry, vol. 31, no. 8, pp. 1049-1056, 1983.

[13] D. Zeuschner, W. J. C. Geerts, E. van Donselaar et al., "Immunoelectron tomography of ER exit sites reveals the existence of free COPII-coated transport carriers," Nature Cell Biology, vol. 8, no. 4, pp. 377-383, 2006.

[14] R. S. Polishchuk, E. V. Polishchuk, P. Marra et al., "Correlative light-electron microscopy reveals the tubular-saccular ultrastructure of carriers operating between Golgi apparatus and plasma membrane," Journal of Cell Biology, vol. 148, no. 1, pp. 45-58, 2000.

[15] B. S. Donohoe, S. Mogelsvang, and L. A. Staehelin, "Electron tomography of ER, Golgi and related membrane systems," Methods, vol. 39, no. 2, pp. 154-162, 2006.

[16] N. K. Gonatas, A. Stieber, and J. O. Gonatas, "Fragmentation of the Golgi apparatus in neurodegenerative diseases and cell death," Journal of the Neurological Sciences, vol. 246, no. 1-2, pp. 21-30, 2006.

[17] M. C. Derby and P. A. Gleeson, "New insights into membrane trafficking and protein sorting," International Review of Cytology, vol. 261, pp. 47-116, 2007.

[18] A. A. Mironov and M. Pavelka, The Golgi Apparatus. State of the Art 110 Years after Camillo Golgi's Discovery, Springer Wien, NewYork, NY, USA, 2008.

[19] E. Papanikou and B. S. Glick, "The yeast Golgi apparatus: insights and mysteries," FEBS Letters, vol. 583, no. 23, pp. 37463751, 2009.

[20] J. H. Wei and J. Seemann, "Mitotic division of the mammalian Golgi apparatus," Seminars in Cell and Developmental Biology, vol. 20, no. 7, pp. 810-816, 2009.

[21] M. Anitei and B. Hoflack, "Exit from the trans-Golgi network: from molecules to mechanisms," Current Opinion in Cell Biology, vol. 23, no. 4, pp. 443-451, 2011.

[22] J. Klumperman, "Architecture of the mammalian Golgi," Cold Spring Harbor Perspectives in Biology, vol. 3, no. 7, Article ID a005181, 2011.
[23] Y. Wang and J. Seemann, "Golgi biogenesis," Cold Spring Harbor Perspectives in Biology, vol. 3, no. 10, Article ID a005330, 2011.

[24] K. W. Moremen, M. Tiemeyer, and A. V. Nairn, "Vertebrate protein glycosylation: diversity, synthesis and function," Nature Reviews Molecular Cell Biology, vol. 13, pp. 448-462, 2012.

[25] A. J. Dalton and M. D. Felix, "A comparative study of the Golgi complex," The Journal of Biophysical and Biochemical Cytology, vol. 2, no. 4, pp. 79-84, 1956.

[26] A. Rambourg, Y. Clermont, and A. Marraud, “Three dimensional structure of the osmium impregnated Golgi apparatus as seen in the high voltage electron microscope," American Journal of Anatomy, vol. 140, no. 1, pp. 27-46, 1974.

[27] A. Rambourg, Y. Clermont, and L. Hermo, "Three-dimensional architecture of the Golgi apparatus in Sertoli cells of the rat," American Journal of Anatomy, vol. 154, no. 4, pp. 455-476, 1979.

[28] M. S. Ladinsky, D. N. Mastronarde, J. R. McIntosh, K. E. Howell, and L. A. Staehelin, "Golgi structure in three dimensions: functional insights from the normal rat kidney cell," Journal of Cell Biology, vol. 144, no. 6, pp. 1135-1149, 1999.

[29] R. S. Taylor, S. M. Jones, R. H. Dahl, M. H. Nordeen, and K. E. Howell, "Characterization of the Golgi complex cleared of proteins in transit and examination of calcium uptake activities," Molecular Biology of the Cell, vol. 8, no. 10, pp. 19111931, 1997.

[30] M. M. Wu, M. Grabe, S. Adams, R. Y. Tsien, H. P. H. Moore, and T. E. Machen, "Mechanisms of $\mathrm{pH}$ regulation in the regulated secretory pathway," Journal of Biological Chemistry, vol. 276, no. 35, pp. 33027-33035, 2001.

[31] J. H. Wei and J. Seemann, "Unraveling the Golgi ribbon,” Traffic, vol. 11, no. 11, pp. 1391-1400, 2010.

[32] A. A. Mironov and G. V. Beznoussenko, "Molecular mechanisms responsible for formation of Golgi ribbon," Histology and Histopathology, vol. 26, no. 1, pp. 117-133, 2011.

[33] B. Storrie, J. White, S. Röttger, E. H. K. Stelzer, T. Suganuma, and T. Nilsson, "Recycling of Golgi-resident glycosyltransferases through the ER reveals a novel pathway and provides an explanation for nocodazole-induced Golgi scattering," Journal of Cell Biology, vol. 143, no. 6, pp. 1505-1521, 1998.

[34] J. Fan, Z. Hu, L. Zeng et al., "Golgi apparatus and neurodegenerative diseases," International Journal of Developmental Neuroscience, vol. 26, no. 6, pp. 523-534, 2008.

[35] Y. Fujita, E. Ohama, M. Takatama, S. Al-Sarraj, and K. Okamoto, "Fragmentation of Golgi apparatus of nigral neurons with $\alpha$-synuclein-positive inclusions in patients with Parkinson's disease," Acta Neuropathologica, vol. 112, no. 3, pp. 261-265, 2006.

[36] G. Thorne-Tjomsland, M. Dumontier, and J. C. Jamieson, "3D topography of noncompact zone Golgi tubules in rat spermatids: a computer-assisted serial section reconstruction study," The Anatomical Record, vol. 250, pp. 381-396, 1998.

[37] A. S. Opat, C. Van Vliet, and P. A. Gleeson, "Trafficking and localisation of resident Golgi glycosylation enzymes," Biochimie, vol. 83, no. 8, pp. 763-773, 2001.

[38] M. G. Farquhar and H. P. Hauri, "Protein sorting and vesicular traffic in the Golgi apparatus," in The Golgi Apparatus, E. Berger and J. Roth, Eds., pp. 63-128, Birkhäuser, Basel, Switzerland, 1997.

[39] G. van Meer, "Lipids of the Golgi membrane," Trends in Cell Biology, vol. 8, no. 1, pp. 29-33, 1998.

[40] J. C. M. Holthuis, T. Pomorski, R. J. Raggers, H. Sprong, and G. Van Meer, "The organizing potential of sphingolipids in 
intracellular membrane transport," Physiological Reviews, vol. 81, no. 4, pp. 1689-1723, 2001.

[41] D. K. Banfield, "Mechanisms of protein retention in the Golgi," Cold Spring Harbor Perspectives in Biology, vol. 3, Article ID a005264, 2011.

[42] D. J. Gill, J. Chia, J. Senewiratne, and F. Bard, "Regulation of O-glycosylation through Golgi-to-ER relocation of initiation enzymes," Journal of Cell Biology, vol. 189, no. 5, pp. 843-858, 2010.

[43] A. Sesso, F. Paulo de Faria, E. S. M. Iwamura, and H. Correa, "A three-dimensional reconstruction study of the rough ER-Golgi interface in serial thin sections of the pancreatic acinar cell of the rat," Journal of Cell Science, vol. 107, no. 3, pp. 517-528, 1994.

[44] Y. Clermont, A. Rambourg, and L. Hermo, "Connections between the various elements of the cis- and mid-compartments of the Golgi apparatus of early rat spermatids," Anatomical Record, vol. 240, no. 4, pp. 469-480, 1994.

[45] A. Rambourg and Y. Clermont, "Three-dimensional structure of the Golgi apparatus in mammalian cells," in The Golgi Apparatus, E. G. Berger and J. Roth, Eds., pp. 37-61, Birkhäuser, Basel, Switzerland, 1997.

[46] G. Vivero-Salmerón, J. Ballesta, and J. A. Martínez-Menárguez, "Heterotypic tubular connections at the endoplasmic reticulum-Golgi complex interface," Histochemistry and Cell Biology, vol. 130, pp. 709-717, 2008.

[47] C. van Vliet, E. C. Thomas, A. Merino-Trigo, R. D. Teasdale, and P. A. Gleeson, "Intracellular sorting and transport of proteins," Progress in Biophysics and Molecular Biology, vol. 83, no. 1, pp. $1-45,2003$.

[48] G. Griffiths, S. Pfeiffer, K. Simons, and K. Matlin, "Exit of newly synthesized membrane proteins from the trans cisterna of the Golgi complex to the plasma membrane," Journal of Cell Biology, vol. 101, no. 3, pp. 949-964, 1985.

[49] G. Griffiths, S. D. Fuller, R. Back, M. Hollinshead, S. Pfeiffer, and K. Simons, "The dynamic nature of the Golgi complex," Journal of Cell Biology, vol. 108, no. 2, pp. 277-297, 1989.

[50] H. J. Geuze and D. J. Morre, “Trans-Golgi reticulum," Journal of Electron Microscopy Technique, vol. 17, no. 1, pp. 24-34, 1991.

[51] Y. Clermont, A. Rambourg, and L. Hermo, "Trans-Golgi network (TGN) of different cell types: three-dimensional structural characteristics and variability," Anatomical Record, vol. 242, no. 3, pp. 289-301, 1995.

[52] R. S. Polishchuk and A. A. Mironov, "Structural aspects of Golgi function," Cellular and Molecular Life Sciences, vol. 61, no. 2, pp. 146-158, 2004.

[53] P. A. Gleeson, J. G. Lock, M. R. Luke, and J. L. Stow, "Domains of the TGN: coats, tethers and G proteins," Traffic, vol. 5, no. 5, pp. 315-326, 2004.

[54] F. Bard and V. Malhotra, "The formation of TGN-to-plasmamembrane transport carriers," Annual Review of Cell and Developmental Biology, vol. 22, pp. 439-455, 2006.

[55] R. D. Klausner, J. G. Donaldson, and J. Lippincott-Schwartz, "Brefeldin A: insights into the control of membrane traffic and organelle structure," Journal of Cell Biology, vol. 116, no. 5, pp. 1071-1080, 1992.

[56] J. Llopis, J. M. McCaffery, A. Miyawaki, M. G. Farquhar, and R. Y. Tsien, "Measurement of cytosolic, mitochondrial, and Golgi $\mathrm{pH}$ in single living cells with green fluorescent proteins," Proceedings of the National Academy of Sciences of the United States of America, vol. 95, no. 12, pp. 6803-6808, 1998.
[57] H. H. Mollenhauer and D. J. Morré, “The tubular network of the Golgi apparatus," Histochemistry and Cell Biology, vol. 109, no. 5-6, pp. 533-543, 1998.

[58] L. Orci, A. Perrelet, and J. E. Rothman, "Vesicles on strings: Morphological evidence for processive transport within the Golgi stack," Proceedings of the National Academy of Sciences of the United States of America, vol. 95, no. 5, pp. 2279-2283, 1998.

[59] Y. Xiang and Y. Wang, "New components of the Golgi matrix," Cell and Tissue Research, vol. 344, no. 3, pp. 365-379, 2011.

[60] N. Nakamura, C. Rabouille, R. Watson et al., "Characterization of a cis-Golgi matrix protein, GM130," Journal of Cell Biology, vol. 131, no. 6, pp. 1715-1726, 1995.

[61] P. Slusarewicz, T. Nilsson, N. Hui, R. Watson, and G. Warren, "Isolation of a matrix that binds medial Golgi enzymes," Journal of Cell Biology, vol. 124, no. 4, pp. 405-413, 1994.

[62] G. Egea and R. M. Rios, "The role of the cytoskeleton in the structure and function of the Golgi apparatus," in The Golgi Apparatus, A. A. Mironov and M. Pavelka, Eds., pp. 270-300, Springer, NewYork, NY, USA, 2008.

[63] M. Lowe, "Structural organization of the Golgi apparatus," Current Opinion in Cell Biology, vol. 23, no. 1, pp. 85-93, 2011.

[64] R. M. Rios and M. Bornens, "The Golgi apparatus at the cell centre," Current Opinion in Cell Biology, vol. 15, pp. 60-66, 2003.

[65] S. Yadav and A. D. Linstedt, "Golgi positioning," Cold Spring Harbor Perspectives in Biology, vol. 3, pp. 1-17, 2011.

[66] J. K. Burkhardt, "The role of microtubule-based motor proteins in maintaining the structure and function of the Golgi complex," Biochimica et Biophysica Acta, vol. 1404, no. 1-2, pp. 113126, 1998.

[67] K. Chabin-Brion, J. Marceiller, F. Perez et al., "The Golgi complex is a microtubule-organizing organelle," Molecular Biology of the Cell, vol. 12, no. 7, pp. 2047-2060, 2001.

[68] S. Rivero, J. Cardenas, M. Bornens, and R. M. Rios, "Microtubule nucleation at the cis-side of the golgi apparatus requires AKAP450 and GM130," The EMBO Journal, vol. 28, no. 8, pp. 1016-1028, 2009.

[69] A. Efimov, A. Kharitonov, N. Efimova et al., "Asymmetric CLASP-dependent nucleation of noncentrosomal microtubules at the trans-Golgi Network," Developmental Cell, vol. 12, no. 6, pp. 917-930, 2007.

[70] P. M. Miller, A. W. Folkmann, A. R. R. Maia, N. Efimova, A. Efimov, and I. Kaverina, "Golgi-derived CLASP-dependent microtubules control Golgi organization and polarized trafficking in motile cells," Nature Cell Biology, vol. 11, no. 9, pp. 10691080, 2009.

[71] F. Valderrama, A. Luna, T. Babià et al., "The Golgi-associated COPI-coated buds and vesicles contain $\beta / \gamma$-actin," Proceedings of the National Academy of Sciences of the United States of America, vol. 97, no. 4, pp. 1560-1565, 2000.

[72] G. Egea, F. Lázaro-Diéguez, and M. Vilella, "Actin dynamics at the Golgi complex in mammalian cells," Current Opinion in Cell Biology, vol. 18, pp. 168-178, 2006.

[73] F. Lázaro-Diéguez, C. Colonna, M. Cortegano, M. Calvo, S. E. Martínez, and G. Egea, "Variable actin dynamics requirement for the exit of different cargo from the trans-Golgi network," FEBS Letters, vol. 581, no. 20, pp. 3875-3881, 2007.

[74] F. Valderrama, J. M. Durán, T. Babià, H. Barth, J. RenauPiqueras, and G. Egea, "Actin microfilaments facilitate the retrogade transport from the Golgi complex to the endoplasmic reticulum in mammalian cells," Traffic, vol. 2, no. 10, pp. 717726, 2001. 
[75] A. Disanza and G. Scita, "Cytoskeletal regulation: coordinating actin and microtubule dynamics in membrane trafficking," Current Biology, vol. 18, no. 18, pp. R873-R875, 2008.

[76] K. G. Campellone, N. J. Webb, E. A. Znameroski, and M. D. Welch, "WHAMM is an Arp2/3 complex activator that binds microtubules and functions in ER to golgi transport," Cell, vol. 134, no. 1, pp. 148-161, 2008.

[77] Q. T. Shen, P. P. Hsiue, C. V. Sindelar, M. D. Welch, K. G. Campellone, and H. W. Wang, "Structural insights into WHAMM-mediated cytoskeletal coordination during membrane remodeling," The Journal of Cell Biology, vol. 199, pp. 111124, 2012.

[78] T. F. Roth and K. R. Porter, "Yolk protein uptake in the oocyte of the mosquito Aedes aegypti L.," The Journal of Cell Biology, vol. 20, pp. 313-332, 1964.

[79] B. M. F. Pearse, "Clathrin: a unique protein associated with intracellular transfer of membrane by coated vesicles," Proceedings of the National Academy of Sciences of the United States of America, vol. 73, no. 4, pp. 1255-1259, 1976.

[80] A. Oprins, R. Duden, T. E. Kreis, H. J. Geuze, and J. W. Slot, " $\beta$-COP localizes mainly to the cis-Golgi side in exocrine pancreas," Journal of Cell Biology, vol. 121, no. 1, pp. 49-60, 1993.

[81] B. M. F. Pearse and M. S. Robinson, "Clathrin, adaptors, and sorting," Annual Review of Cell Biology, vol. 6, pp. 151-171, 1990.

[82] T. Braulke and J. S. Bonifacino, "Sorting of lysosomal proteins," Biochimica et Biophysica Acta, vol. 1793, no. 4, pp. 605-614, 2009.

[83] T. Kirchhausen, "Clathrin," Annual Review of Biochemistry, vol. 69, pp. 699-727, 2000.

[84] E. Rodriguez-Boulan and A. Müsch, "Protein sorting in the Golgi complex: shifting paradigms," Biochimica et Biophysica Acta, vol. 1744, no. 3, pp. 455-464, 2005.

[85] M. A. McNiven, H. Cao, K. R. Pitts, and Y. Yoon, "The dynamin family of mechanoenzymes: pinching in new places," Trends in Biochemical Sciences, vol. 25, no. 3, pp. 115-120, 2000.

[86] E. Eisenberg and L. E. Greene, "Multiple roles of auxilin and Hsc70 in clathrin-mediated endocytosis," Traffic, vol. 8, no. 6, pp. 640-646, 2007.

[87] C. Barlowe, L. Orci, T. Yeung et al., "COPII: a membrane coat formed by sec proteins that drive vesicle budding from the endoplasmic reticulum," Cell, vol. 77, no. 6, pp. 895-907, 1994.

[88] L. C. Bickford, E. Mossessova, and J. Goldberg, "A structural view of the COPII vesicle coat," Current Opinion in Structural Biology, vol. 14, no. 2, pp. 147-153, 2004.

[89] D. Jensen and R. Schekman, "COPII-mediated vesicle formation at a glance," Journal of Cell Science, vol. 124, no. 1, pp. 1-4, 2011.

[90] T. Kirchhausen, "Making COPII coats," Cell, vol. 129, no. 7, pp. 1251-1252, 2007.

[91] C. Barlowe, "COPII and selective export from the endoplasmic reticulum," Biochimica et Biophysica Acta, vol. 1404, no. 1-2, pp. 67-76, 1998.

[92] J. A. Martínez-Menárguez, H. J. Geuze, J. W. Slot, and J. Klumperman, "Vesicular tubular clusters between the ER and Golgi mediate concentration of soluble secretory proteins by exclusion from COPI-coated vesicles," Cell, vol. 98, no. 1, pp. 8190, 1999.

[93] K. Saito, M. Chen, F. Bard et al., "TANGO1 facilitates cargo loading at endoplasmic reticulum exit sites," Cell, vol. 136, no. 5, pp. 891-902, 2009.

[94] L. Jin, K. B. Pahuja, K. E. Wickliffe et al., "Ubiquitin-dependent regulation of COPII coat size and function," Nature, vol. 482, pp. 495-500, 2012.
[95] H. P. Hauri and A. Schweizer, "The endoplasmic reticulumGolgi intermediate compartment," Current Opinion in Cell Biology, vol. 4, no. 4, pp. 600-608, 1992.

[96] S. I. Bannykh, T. Rowe, and W. E. Balch, "The organization of endoplasmic reticulum export complexes," Journal of Cell Biology, vol. 135, no. 1, pp. 19-35, 1996.

[97] J. Saraste and E. Kuismanen, "Pre- and post-Golgi vacuoles operate in the transport of Semliki Forest virus membrane glycoproteins to the cell surface," Cell, vol. 38, no. 2, pp. 535549, 1984.

[98] A. Schweizer, J. A. M. Fransen, K. Matter, T. E. Kreis, L. Ginsel, and H. P. Hauri, "Identification of an intermediate compartment involved in protein transport from endoplasmic reticulum to Golgi apparatus," European Journal of Cell Biology, vol. 53, no. 2, pp. 185-196, 1990.

[99] H. Ben-Takaya, K. Miura, R. Pepperkok, and H. P. Hauri, "Live imaging of bidirectional traffic from the ERGIC," Journal of Cell Science, vol. 118, no. 2, pp. 357-367, 2005.

[100] Y. C. Zhang, Y. Zhou, C. Z. Yang, and D. S. Xiong, "A review of ERGIC-53: its structure, functions, regulation and relations with diseases," Histology and Histopathology, vol. 24, no. 9, pp. 1193-1204, 2009.

[101] J. F. Presley, N. B. Cole, T. A. Schroer, K. Hirschberg, K. J. M. Zaal, and J. Lippincott-Schwartz, "ER-to-Golgi transport visualized in living cells," Nature, vol. 389, no. 6646, pp. 81-85, 1997.

[102] J. A. Martínez-Menárguez, H. J. Geuze, and J. Ballesta, "Identification of two types of beta-COP vesicles in the Golgi complex of rat spermatids," European Journal of Cell Biology, vol. 71, pp. 137-143, 1996.

[103] J. Lippincott-Schwartz, J. G. Donaldson, A. Schweizer et al., "Microtubule-dependent retrograde transport of proteins into the ER in the presence of brefeldin A suggests an ER recycling pathway," Cell, vol. 60, no. 5, pp. 821-836, 1990.

[104] A. Girod, B. Storrie, J. C. Simpson et al., "Evidence for a COPI-independent transport route from the Golgi complex to the endoplasmic reticulum," Nature Cell Biology, vol. 1, no. 7, pp. 423-430, 1999.

[105] V. Popoff, F. Adolf, B. Brügger, and F. Wieland, "COPI budding within the Golgi stack," Cold Spring Harbor Perspectives in Biology, vol. 3, Article ID a005231, 2011.

[106] J. Moelleken, J. Malsam, M. J. Betts et al., "Differential localization of coatomer complex isoforms within the Golgi apparatus," Proceedings of the National Academy of Sciences of the United States of America, vol. 104, no. 11, pp. 4425-4430, 2007.

[107] L. Orci, B. S. Glick, and J. E. Rothman, "A new type of coated vesicular carrier that appears not to contain clathrin: its possible role in protein transport within the Golgi stack," Cell, vol. 46, no. 2, pp. 171-184, 1986.

[108] V. Malhotra, T. Serafini, L. Orci, J. C. Shepherd, and J. E. Rothman, "Purification of a novel class of coated vesicles mediating biosynthetic protein transport through the Golgi stack," Cell, vol. 58, no. 2, pp. 329-336, 1989.

[109] M. G. Waters, T. Serafini, and J. E. Rothman, “Coatomer': a cytosolic protein complex containing subunits of non-clathrincoated Golgi transport vesicles," Nature, vol. 349, no. 6306, pp. 248-251, 1991.

[110] T. Serafini, L. Orci, M. Amherdt, M. Brunner, R. A. Kahn, and J. E. Rothman, "ADP-ribosylation factor is a subunit of the coat of Golgi-derived COP-coated vesicles: a novel role for a GTPbinding protein," Cell, vol. 67, no. 2, pp. 239-253, 1991. 
[111] C. L. Jackson and J. E. Casanova, "Turning on ARF: the Sec7 family of guanine-nucleotide-exchange factors," Trends in Cell Biology, vol. 10, no. 2, pp. 60-67, 2000.

[112] K. Kawamoto, Y. Yoshida, H. Tamaki et al., "GBF1, a guanine nucleotide exchange factor for ADP-ribosylation factors, is localized to the cis-Golgi and involved in membrane association of the COPI coat," Traffic, vol. 3, no. 7, pp. 483-495, 2002.

[113] R. García-Mata, T. Szul, C. Alvarez, and E. Sztul, "ADPribosylation factor/COPI-dependent events at the endoplasmic reticulum-Golgi interface are regulated by the guanine nucleotide exchange factor GBF1," Molecular Biology of the Cell, vol. 14, no. 6, pp. 2250-2261, 2003.

[114] H. Inoue and P. A. Randazzo, "Arf GAPs and their interacting proteins," Traffic, vol. 8, no. 11, pp. 1465-1475, 2007.

[115] G. Tanigawa, L. Orci, M. Amherdt, M. Ravazzola, J. B. Helms, and J. E. Rothman, "Hydrolysis of bound GTP by ARF protein triggers uncoating of Golgi- derived COP-coated vesicles," Journal of Cell Biology, vol. 123, no. 6, pp. 1365-1371, 1993.

[116] Y. Shiba and P. A. Randazzo, "ArfGAP1 function in COPI mediated membrane traffic: currently debated models and comparison to other coat-binding ArfGAPs," Histology and Histopathology, vol. 27, pp. 1143-1153, 2012.

[117] J. Bigay, P. Gounon, S. Roblneau, and B. Antonny, "Lipid packing sensed by ArfGAP1 couples COPI coat disassembly to membrane bilayer curvature," Nature, vol. 426, no. 6966, pp. 563-566, 2003.

[118] W. Nickel, J. Malsam, K. Gorgas et al., "Uptake by COPI-coated vesicles of both anterograde and retrograde cargo is inhibited by GTP $\gamma$ S in vitro," Journal of Cell Science, vol. 111, no. 20, pp. 3081-3090, 1998

[119] R. Beck, M. Rawet, F. T. Wieland, and D. Cassel, "The COPI system: molecular mechanisms and function," FEBS Letters, vol. 583, pp. 2701-2709, 2009.

[120] F. Letourneur, E. C. Gaynor, S. Hennecke et al., "Coatomer is essential for retrieval of dilysine-tagged proteins to the endoplasmic reticulum," Cell, vol. 79, no. 7, pp. 1199-1207, 1994.

[121] R. Schindler, C. Itin, M. Zerial, F. Lottspeich, and H. P. Hauri, "ERGIC-53, a membrane protein of the ER-Golgi intermediate compartment, carries an ER retention motif," European Journal of Cell Biology, vol. 61, no. 1, pp. 1-9, 1993.

[122] L. P. Jackson, M. Lewis, H. M. Kent et al., "Molecular basis for recognition of dilysine trafficking motifs by COPI," Developmental Cell, vol. 23, pp. 1-8, 2012.

[123] W. Nickel, K. Sohn, C. Bünning, and F. T. Wieland, "p23, A major COPI-vesicle membrane protein, constitutively cycles through the early secretory pathway," Proceedings of the National Academy of Sciences of the United States of America, vol. 94, no. 21, pp. 11393-11398, 1997.

[124] J. C. Semenza, K. G. Hardwick, N. Dean, and H. R. B. Pelham, "ERD2, a yeast gene required for the receptor-mediated retrieval of luminal ER proteins from the secretory pathway," Cell, vol. 61, no. 7, pp. 1349-1357, 1990.

[125] I. Majoul, M. Straub, S. W. Hell, R. Duden, and H. D. Söling, "KDEL-cargo regulates interactions between proteins involved in COPI vesicle traffic: measurements in living cells using FRET,' Developmental Cell, vol. 1, no. 1, pp. 139-153, 2001.

[126] B. S. Glick, "Organization of the Golgi apparatus," Current Opinion in Cell Biology, vol. 12, no. 4, pp. 450-456, 2000.

[127] R. Blum, D. J. Stephens, and I. Schulz, "Lumenal targeted GFP, used as a marker of soluble cargo, visualises rapid ERGIC to Golgi traffic by a tubulo-vesicular network," Journal of Cell Science, vol. 113, no. 18, pp. 3151-3159, 2000.
[128] J. C. Simpson, T. Nilsson, and R. Pepperkok, "Biogenesis of tubular ER-to-golgi transport intermediates," Molecular Biology of the Cell, vol. 17, no. 2, pp. 723-737, 2006.

[129] K. Hirschberg, C. M. Miller, J. Ellenberg et al., "Kinetic analysis of secretory protein traffic and characterization of Golgi to plasma membrane transport intermediates in living cells," Journal of Cell Biology, vol. 143, no. 6, pp. 1485-1503, 1998.

[130] D. Toomre, P. Keller, J. White, J. C. Olivo, and K. Simons, "Dualcolor visualization of trans-Golgi network to plasma membrane traffic along microtubules in living cells," Journal of Cell Science, vol. 112, no. 1, pp. 21-33, 1999.

[131] L. Hermo, A. Rambourg, and Y. Clermont, "Three-dimensional architecture of the cortical region of the Golgi apparatus in rat spermatids," American Journal of Anatomy, vol. 157, no. 4, pp. 357-373, 1980.

[132] M. S. Cooper, A. H. Cornell-Bell, A. Chernjavsky, J. W. Dani, and S. J. Smith, "Tubulovesicular processes emerge from transGolgi cisternae, extend along microtubules, and interlink adjacent trans-Golgi elements into a reticulum," Cell, vol. 61, no. 1, pp. 135-145, 1990.

[133] N. B. Cole, C. L. Smith, N. Sciaky, M. Terasaki, M. Edidin, and J. Lippincott-Schwartz, "Diffusional mobility of Golgi proteins in membranes of living cells," Science, vol. 273, no. 5276, pp. 797801,1996

[134] S. J. Scales, R. Pepperkok, and T. E. Kreis, "Visualization of ERto-Golgi transport in living cells reveals a sequential mode of action for COPII and COPI," Cell, vol. 90, no. 6, pp. 1137-1148, 1997.

[135] M. S. Ladinsky, J. R. Kremer, P. S. Furcinitti, J. R. McIntosh, and K. E. Howell, "HVEM tomography of the trans-Golgi network: structural insights and identification of a lace-like vesicle coat," Journal of Cell Biology, vol. 127, no. 1, pp. 29-38, 1994.

[136] A. Trucco, R. S. Polischuck, O. Martella et al., "Secretory traffic triggers the formation of tubular continuities across Golgi subcompartments," Nature Cell Biology, vol. 6, no. 11, pp. 1071-1081, 2004.

[137] B. J. Marsh, N. Volkmann, J. R. McIntosh, and K. E. Howell, "Direct continuities between cisternae at different levels of the Golgi complex in glucose-stimulated mouse islet beta cells," Proceedings of the National Academy of Sciences of the United States of America, vol. 101, no. 15, pp. 5565-5570, 2004.

[138] E. Martínez-Alonso, G. Egea, J. Ballesta, and J. A. MartínezMenárguez, "Structure and dynamics of the Golgi complex at 15 degrees C: low temperature induces the formation of Golgiderived tubules," Traffic, vol. 6, pp. 32-44, 2005.

[139] E. Martínez-Alonso, J. Ballesta, and J. A. Martínez-Menárguez, "Low-temperature-induced Golgi tubules are transient membranes enriched in molecules regulating intra-Golgi transport," Traffic, vol. 8, no. 4, pp. 359-368, 2007.

[140] T. E. Kreis, "Regulation of vesicular and tubular membrane traffic of the Golgi complex by coat proteins," Current Opinion in Cell Biology, vol. 4, no. 4, pp. 609-615, 1992.

[141] M. Lowe and T. E. Kreis, "Regulation of membrane traffic in animal cells by COPI," Biochimica et Biophysica Acta, vol. 1404, no. 1-2, pp. 53-66, 1998.

[142] M. Krauss, J. Y. Jia, A. Roux et al., "Arf1-GTP-induced tubule formation suggests a function of arf family proteins in curvature acquisition at sites of vesicle budding," Journal of Biological Chemistry, vol. 283, no. 41, pp. 27717-27723, 2008.

[143] A. Roux, G. Cappello, J. Cartaud, J. Prost, B. Goud, and P. Bassereau, "A minimal system allowing tubulation with 
molecular motors pulling on giant liposomes," Proceedings of the National Academy of Sciences of the United States of America, vol. 99, no. 8, pp. 5394-5399, 2002.

[144] P. de Figueiredo, D. Drecktrah, R. S. Polizotto, N. B. Cole, J. Lippincott-Schwartz, and W. J. Brown, "Phospholipase $\mathrm{A}_{2}$ antagonists inhibit constitutive retrograde membrane traffic to the reticulum," Traffic, vol. 1, no. 6, pp. 504-511, 2000.

[145] W. J. Brown, K. Chambers, and A. Doody, "Phospholipase A2 (PLA2) enzymes in membrane trafficking: mediators of membrane shape and function," Traffic, vol. 4, no. 4, pp. 214-221, 2003.

[146] E. San Pietro, M. Capestrano, E. V. Polishchuk et al., "Group IV phospholipase A $2 \alpha$ controls the formation of inter-cisternal continuities involved in intra-golgi transport," PLoS Biology, vol. 7, no. 9, Article ID e1000194, 2009.

[147] J. A. Schmidt, D. N. Kalkofen, K. W. Donovan, and W. J. Brown, "A role for phospholipase $\mathrm{A}_{2}$ activity in membrane tubule formation and TGN trafficking," Traffic, vol. 11, no. 12, pp. 15301536, 2010.

[148] C. L. Baron and V. Malhotra, "Role of diacylglycerol in PKD recruitment to the TGN and protein transport to the plasma membrane," Science, vol. 295, no. 5553, pp. 325-328, 2002.

[149] I. Fernández-Ulibarri, M. Vilella, F. Lázaro-Diéguez et al., "Diacylglycerol is required for the formation of COPI vesicles in the Golgi-to-ER transport pathway," Molecular Biology of the Cell, vol. 18, no. 9, pp. 3250-3263, 2007.

[150] J. S. Yang, H. Gad, S. Y. Lee et al., "A role for phosphatidic acid in COPI vesicle fission yields insights into Golgi maintenance," Nature Cell Biology, vol. 10, no. 10, pp. 1146-1153, 2008.

[151] J. S. Yang, C. Valente, R. S. Polishchuk et al., "COPI acts in both vesicular and tubular transport," Nature Cell Biology, vol. 13, no. 8, pp. 996-1003, 2011.

[152] M. Tomás, E. Martínez-Alonso, J. Ballesta, and J. A. MartínezMenárguez, "Regulation of ER-Golgi intermediate compartment tubulation and mobility by COPI coats, motor proteins and microtubules," Traffic, vol. 11, pp. 616-625, 2010.

[153] H. Ben-Tekaya, R. A. Kahn, and H. P. Hauri, "ADP ribosylation factors 1 and 4 and group VIA phospholipase A2 regulate morphology and intraorganellar traffic in the endoplasmic reticulum-golgi intermediate compartment," Molecular Biology of the Cell, vol. 21, no. 23, pp. 4130-4140, 2010.

[154] E. V. Polishchuk, A. Di Pentima, A. Luini, and R. S. Polishchuk, "Mechanism of constitutive export from the golgi: bulk flow via the formation, protrusion, and en bloc cleavage of large transgolgi network tubular domains," Molecular Biology of the Cell, vol. 14, no. 11, pp. 4470-4485, 2003.

[155] A. A. Mironov, A. A. Mironov Jr., G. V. Beznoussenko et al., "ER-to-Golgi carriers arise through direct en bloc protrusion and multistage maturation of specialized ER exit domains," Dev. Cell, vol. 5, pp. 583-594, 2003.

[156] H. Horstmann, C. P. Ng, B. L. Tang, and W. Hong, "Ultrastructural characterization of endoplasmic reticulum-Golgi transport containers (EGTC)," Journal of Cell Science, vol. 115, no. 22, pp. 4263-4273, 2002.

[157] J. S. Bonifacino and B. S. Glick, "The mechanisms of vesicle budding and fusion," Cell, vol. 116, no. 2, pp. 153-166, 2004.

[158] W. Hong, "SNAREs and traffic," Biochimica et Biophysica Acta, vol. 1744, no. 3, pp. 493-517, 2005.

[159] R. Jahn and R. H. Scheller, "SNAREs-engines for membrane fusion," Nature Reviews Molecular Cell Biology, vol. 7, no. 9, pp. 631-643, 2006.
[160] J. Malsam and T. H. Söllner, "Organization of SNAREs within the Golgi stack," Cold Spring Harbor Perspectives in Biology, vol. 3, Article ID a005249, 2011.

[161] A. Volchuk, M. Ravazzola, A. Perrelet et al., "Countercurrent distribution of two distinct SNARE complexes mediating transport within the Golgi stack," Molecular Biology of the Cell, vol. 15, no. 4, pp. 1506-1518, 2004.

[162] O. Laufman, A. Kedan, W. Hong, and S. Lev, "Direct interaction between the COG complex and the SM protein, Slyl, is required for Golgi SNARE pairing," The EMBO Journal, vol. 28, no. 14, pp. 2006-2017, 2009.

[163] H. Stenmark, "Rab GTPases as coordinators of vesicle traffic," Nature Reviews Molecular Cell Biology, vol. 10, no. 8, pp. 513525, 2009.

[164] M. Zerial and H. McBride, "Rab proteins as membrane organizers," Nature Reviews Molecular Cell Biology, vol. 2, no. 2, pp. 107-117, 2001.

[165] S. Liu and B. Storrie, "Are Rab proteins the link between Golgi organization and membrane trafficking?" Cell, vol. 69, no. 24, pp. 4093-4106, 2012.

[166] M. Tomás, M. P. Marín, E. Martínez-Alonso et al., "Alcohol induces Golgi fragmentation in differentiated PC12 cells by deregulating Rabl-dependent ER-to-Golgi transport," Histochemistry and Cell Biology, vol. 138, pp. 489-501, 2012.

[167] W. O. Rendón, E. Martínez-Alonso, M. Tomás, N. MartínezMartínez, and J. A. Martínez-Menárguez, "Golgi fragmentation is Rab and SNARE dependent in cellular models of Parkinson's disease," Histochemistry and Cell Biology, 2012.

[168] O. Martinez, A. Schmidt, J. Salaméro, B. Hoflack, M. Roa, and B. Goud, "The small GTP-binding protein rab6 functions in intraGolgi transport," Journal of Cell Biology, vol. 127, no. 6 I, pp. 1575-1588, 1994.

[169] J. White, L. Johannes, F. Mallard et al., "Rab6 coordinates a novel Golgi to ER retrograde transport pathway in live cells," Journal of Cell Biology, vol. 147, no. 4, pp. 743-759, 1999.

[170] I. Grigoriev, D. Splinter, N. Keijzer et al., "Rab6 regulates transport and targeting of exocytotic carriers," Developmental Cell, vol. 13, no. 2, pp. 305-314, 2007.

[171] S. Miserey-Lenkei, G. Chalancon, S. Bardin, E. Formstecher, B. Goud, and A. Echard, "Rab and actomyosin-dependent fission of transport vesicles at the golgi complex," Nature Cell Biology, vol. 12, no. 7, pp. 645-654, 2010.

[172] I. Grigoriev, K. L. Yu, E. Martinez-Sanchez et al., "Rab6, Rab8, and MICAL3 cooperate in controlling docking and fusion of exocytotic carriers," Current Biology, vol. 2, pp. 967-974, 2011.

[173] B. Storrie, M. Micaroni, G. P. Morgan et al., "Electron tomography reveals that Rab6 is essential to the trafficking of transGolgi clathrin and COPI-coated vesicles and the maintenance of Golgi cisternal number," Traffic, vol. 13, pp. 727-744, 2012.

[174] J. Y. Zheng, T. Koda, T. Fujiwara, M. Kishi, Y. Ikehara, and M. Kakinuma, "A novel Rab GTPase, Rab33B, is ubiquitously expressed and localized to the medial Golgi cisternae," Journal of Cell Science, vol. 111, no. 8, pp. 1061-1069, 1998.

[175] T. Starr, Y. Sun, N. Wilkins, and B. Storrie, "Rab33b and Rab6 are functionally overlapping regulators of Golgi homeostasis and trafficking," Traffic, vol. 11, no. 5, pp. 626-636, 2010.

[176] G. V. Pusapati, G. Luchetti, and S. R. Pfeffer, "Ric1/Rgp1 complex: a guanine nucleotide exchange factor for the late Golgi Rab6A GTPase and an effector of the medial Golgi Rab33B GTPase," The Journal of Biological Chemistry, vol. 287, no. 50, pp. 42129-42137, 2012. 
[177] E. Sztul and V. Lupashin, "Role of vesicle tethering factors in the ER-Golgi membrane traffic," FEBS Letters, vol. 583, no. 23, pp. 3770-3783, 2009.

[178] I. Barinaga-Rementeria Ramirez and M. Lowe, "Golgins and GRASPs: holding the Golgi together," Seminars in Cell and Developmental Biology, vol. 20, no. 7, pp. 770-779, 2009.

[179] M. A. De Matteis, A. A. Mironov, and G. V. Beznoussenko, "The Golgi ribbon and the function of the golgins," in The GolgiApparatus, A. A. Mironov and M. Pavelka, Eds., pp. 223-246, Springer, NewYork, NY, USA, 2008.

[180] V. J. Miller and D. Ungar, "Re'COG'nition at the Golgi," Traffic, vol. 13, pp. 891-897, 2012.

[181] M. Sacher, Y. G. Kim, A. Lavie, B. H. Oh, and N. Segev, "The TRAPP complex: insights into its architecture and function," Traffic, vol. 9, no. 12, pp. 2032-2042, 2008.

[182] J. E. Rothman and F. T. Wieland, "Protein sorting by transport vesicles," Science, vol. 272, no. 5259, pp. 227-234, 1996.

[183] J. E. Rothman and L. Orci, "Molecular dissection of the secretory pathway," Nature, vol. 355, no. 6359, pp. 409-415, 1992.

[184] P. Chardin and F. McCormick, "Brefeldin A: the advantage of being uncompetitive," Cell, vol. 97, no. 2, pp. 153-155, 1999.

[185] P. Cosson and F. Letourneur, "Coatomer interaction with Dilysine endoplasmic reticulum retention motifs," Science, vol. 263, no. 5153, pp. 1629-1632, 1994.

[186] L. Orci, M. Ravazzola, A. Volchuk et al., "Anterograde flow of cargo across the Golgi stack potentially mediated via bidirectional "percolating" COPI vesicles," Proceedings of the National Academy of Sciences of the United States of America, vol. 97, no. 19, pp. 10400-10405, 2000.

[187] L. Orci, M. Stamnes, M. Ravazzola et al., "Bidirectional transport by distinct populations of COPI-coated vesicles," Cell, vol. 90, no. 2, pp. 335-349, 1997.

[188] J. A. Martínez-Menárguez, R. Prekeris, V. M. J. Oorschot et al., "Peri-Golgi vesicles contain retrograde but not anterograde proteins consistent with the cisternal progression model of intra-Golgi transport," Journal of Cell Biology, vol. 155, no. 7, pp. 1213-1224, 2001.

[189] P. Cosson, M. Amherdt, J. E. Rothman, and L. Orci, "A resident Golgi protein is excluded from peri-Golgi vesicles in NRK cells," Proceedings of the National Academy of Sciences of the United States of America, vol. 99, no. 20, pp. 12831-12834, 2002.

[190] L. Bonfanti, A. A. Mironov, J. A. Martínez-Menárguez et al., "Procollagen traverses the Golgi stack without leaving the lumen of cisternae: evidence for cisternal maturation," Cell, vol. 95, no. 7, pp. 993-1003, 1998.

[191] M. Melkonian, B. Becker, and D. Becker, "Scale formation in algae," Journal of Electron Microscopy Technique, vol. 17, no. 2, pp. 165-178, 1991.

[192] A. Volchuk, M. Amherdt, M. Ravazzola et al., "Megavesicles implicated in the rapid transport of intracisternal aggregates across the Golgi stack," Cell, vol. 102, no. 3, pp. 335-348, 2000.

[193] P. P. Grasse, "Ultrastructure, polarity and reproduction of Golgi apparatus," Comptes Rendus Hebdomadaires des Séances de l'Académie des Sciences, vol. 245, no. 16, pp. 1278-1281, 1957.

[194] B. S. Glick and V. Malhotra, "The curious status of the Golgi apparatus," Cell, vol. 95, no. 7, pp. 883-889, 1998.

[195] B. S. Glick, T. Elston, and G. Oster, "A cisternal maturation mechanism can explain the asymmetry of the Golgi stack," FEBS Letters, vol. 414, no. 2, pp. 177-181, 1997.

[196] E. Losev, C. A. Reinke, J. Jellen, D. E. Strongin, B. J. Bevis, and B. S. Glick, "Golgi maturation visualized in living yeast," Nature, vol. 441, no. 7096, pp. 1002-1006, 2006.
[197] K. Matsuura-Tokita, M. Takeuchi, A. Ichihara, K. Mikuriya, and A. Nakano, "Live imaging of yeast Golgi cisternal maturation," Nature, vol. 441, no. 7096, pp. 1007-1010, 2006.

[198] H. R. B. Pelham and J. E. Rothman, “The debate about transport in the golgi-two sides of the same coin?" Cell, vol. 102, no. 6, pp. 713-719, 2000.

[199] G. H. Patterson, K. Hirschberg, R. S. Polishchuk, D. Gerlich, R. D. Phair, and J. Lippincott-Schwartz, "Transport through the Golgi apparatus by rapid partitioning within a two-phase membrane System," Cell, vol. 133, no. 6, pp. 1055-1067, 2008.

[200] A. A. Mironov and G. V. Beznoussenko, "The kiss-and-run model of intra-Golgi transport," International Journal of Molecular Sciences, vol. 13, pp. 6800-6819, 2012.

[201] G. Griffiths, "Gut thoughts on the golgi complex," Traffic, vol. 1, no. 9, pp. 738-745, 2000.

[202] C. Golgi, "Sur la structure des cellules nerveuses," Archives Italiennes de Biologie, vol. 30, pp. 60-71, 1898. 

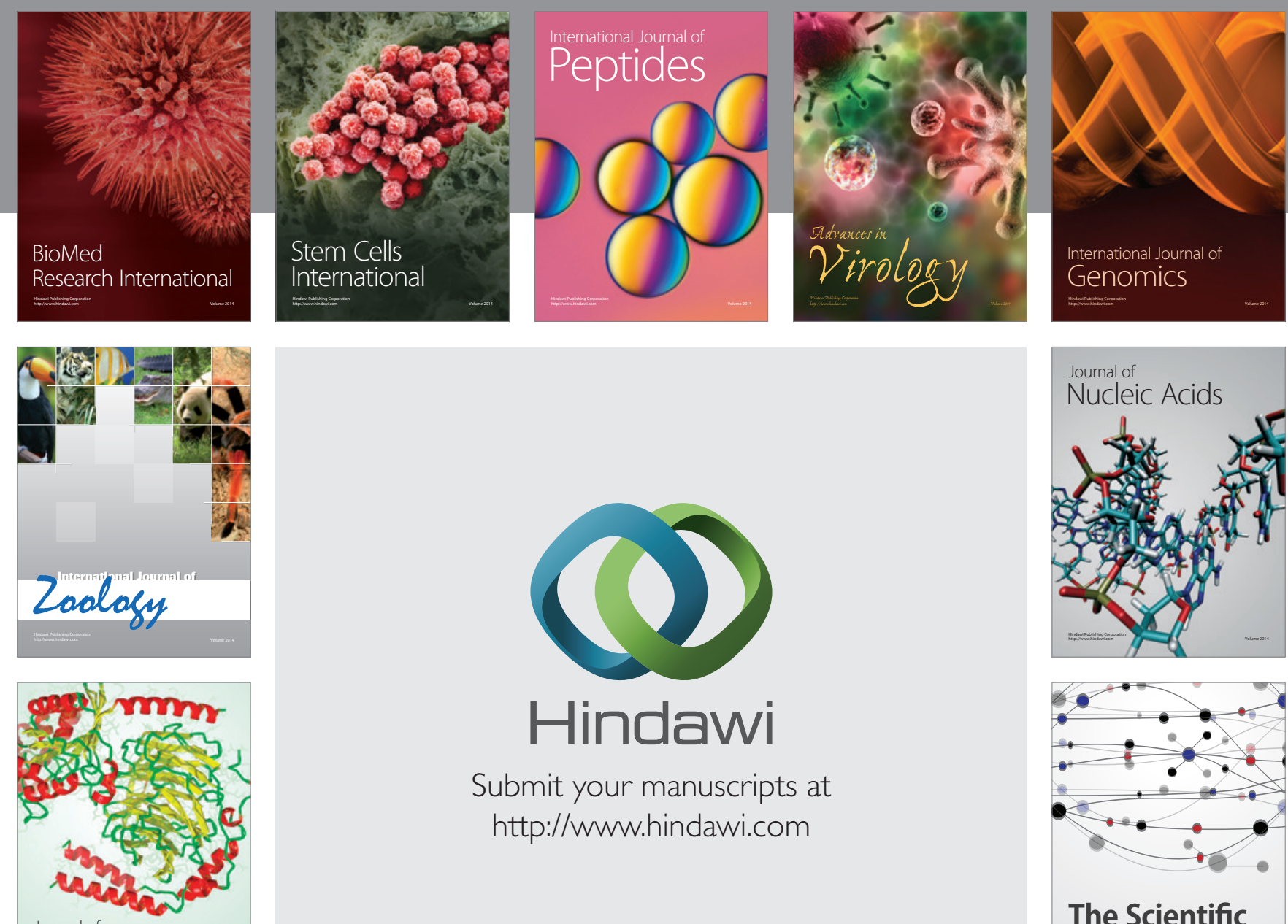

Submit your manuscripts at

http://www.hindawi.com

Journal of
Signal Transduction
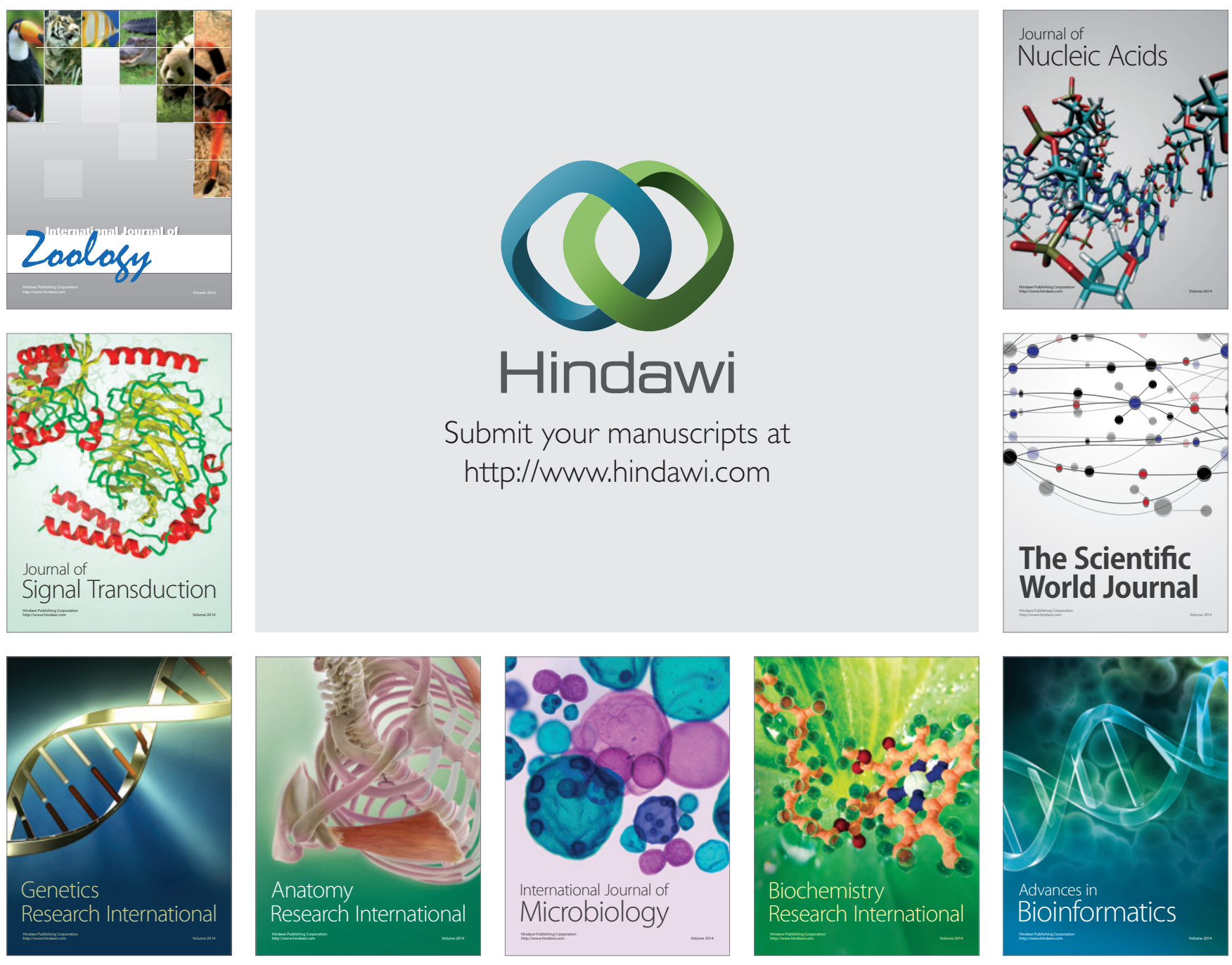

The Scientific World Journal
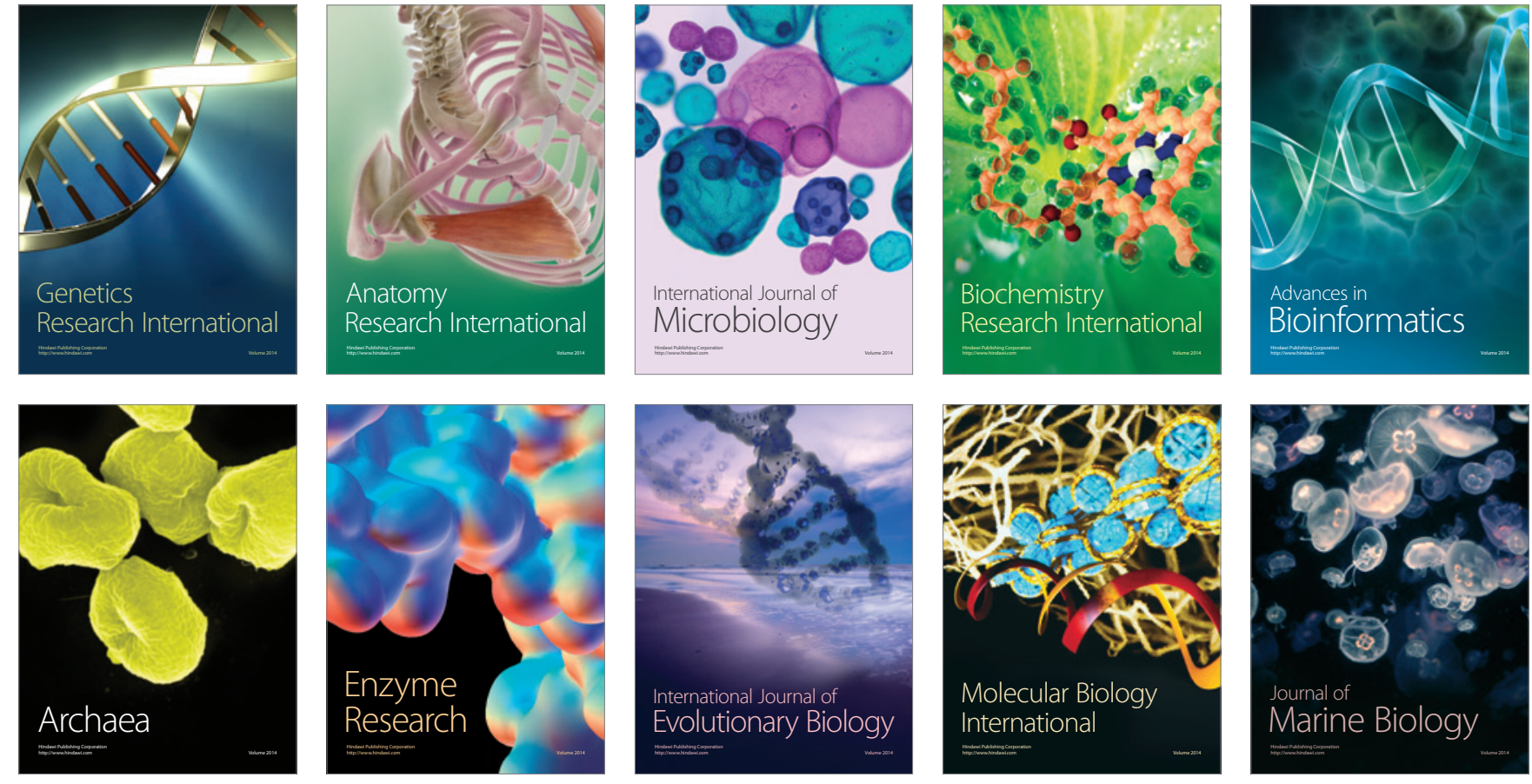